NBER WORKING PAPER SERIES

\title{
OPTIMAL MONETARY POLICY WITH ENDOGENOUS ENTRY AND PRODUCT VARIETY
}

Florin O. Bilbiie

Ippei Fujiwara

Fabio Ghironi

Working Paper 17489

http://www.nber.org/papers/w17489

\author{
NATIONAL BUREAU OF ECONOMIC RESEARCH \\ 1050 Massachusetts Avenue \\ Cambridge, MA 02138 \\ October 2011
}

Previously circulated as "Re-Thinking Price Stability in an Economy with Endogenous Firm Entry: Real Imperfections under Product Variety." First draft: November 2007. For helpful comments and discussions, we thank Klaus Adam, Robert Amano, Kosuke Aoki, Pierpaolo Benigno, Jeffrey Campbell, Lawrence Christiano, Sanjay Chugh, Martin Eichenbaum, Jordi Galí, Christian Hellwig, Jinill Kim, Andrew Levin, Vivien Lewis, Joseph Pearlman, Paolo Pesenti, Celine Poilly, Franck Portier, Gilles Saint-Paul, Frank Smets, Pedro Teles, Henning Weber, Michael Woodford, Tack Yun, and participants in seminars at Amsterdam University/Tinbergen Institute, Bank of Korea, Bank of Portugal, Federal Reserve Bank of Boston, Riksbank Sweden, Toulouse School of Economics, University of Reading, Université Catholique de Louvain/CORE, and the Bank of Canada-ECB conference on "Defining Price Stability: Theoretical Options and Practical Experiences." Bilbiie thanks the Banque de France for financial support through the Chaire Banque de France at the Paris School of Economics and Ghironi thanks the NSF for financial support through a grant to the NBER. Work on this paper was done while Fujiwara was Director and Senior Economist at the Bank of Japan, and Ghironi was a Visiting Scholar at the Federal Reserve Bank of Boston. The support of these institutions is also acknowledged with gratitude. The views expressed in this paper are those of the authors and do not necessarily reflect official views or policies of the Banque de France, the Bank of Japan, the Federal Reserve Bank of Boston, the Federal Reserve System, the Centre for Economic Policy Research, or the National Bureau of Economic Research.

NBER working papers are circulated for discussion and comment purposes. They have not been peerreviewed or been subject to the review by the NBER Board of Directors that accompanies official NBER publications.

(C) 2011 by Florin O. Bilbiie, Ippei Fujiwara, and Fabio Ghironi. All rights reserved. Short sections of text, not to exceed two paragraphs, may be quoted without explicit permission provided that full credit, including $\odot$ notice, is given to the source. 
Optimal Monetary Policy with Endogenous Entry and Product Variety

Florin O. Bilbiie, Ippei Fujiwara, and Fabio Ghironi

NBER Working Paper No. 17489

October 2011

JEL No. E31,E32,E52

\begin{abstract}
$\underline{\text { ABSTRACT }}$
We show that deviations from long-run stability of product prices are optimal in the presence of endogenous producer entry and product variety in a sticky-price model with monopolistic competition in which price stability would be optimal in the absence of entry. Specifically, a long-run positive (negative) rate of inflation is optimal when the benefit of variety to consumers falls short of (exceeds) the market incentives for creating that variety under flexible prices, governed by the desired markup. Plausible preference specifications and parameter values justify a long-run inflation rate of two percent or higher. Price indexation implies even larger deviations from long-run price stability. However, price stability (around this non-zero trend) is close to optimal in the short run, even in the presence of time-varying flexible-price markups that distort the allocation of resources across time and states. The central bank uses its leverage over real activity in the long run, but not in the short run. Our results point to the need for continued empirical research on the determinants of markups and investigation of the benefit of product variety to consumers.
\end{abstract}

Florin O. Bilbiie

Université Paris 1 Panthéon-Sorbonne

Centre d'Economie de la Sorbonne

106/112 Boulevard de l'Hôpital

75647 Paris Cedex 13

France

florin.bilbiie@univ-paris1.fr

Ippei Fujiwara

Australian National University

Crawford School of Economics and Government

Lennox Crossing, Building \#132

Canberra ACT 0200, Australia

ippei.fujiwara@anu.edu.au
Fabio Ghironi

Boston College

Department of Economics

140 Commonwealth Avenue

Chestnut Hill, MA 02467-3859

United States

and NBER

fabio.ghironi@bc.edu 


\section{Introduction}

A recent, fast growing literature argues that changes in the range of available product varieties contribute significantly to economic dynamics and movements in prices over time spans usually associated with the length of business cycles (Bilbiie, Ghironi, and Melitz, 2007, Broda and Weinstein, 2010, and references therein). In the light of this literature, the question of how to conduct economic policy optimally in economies with endogenous producer entry and product variety arises naturally. This paper investigates this question from the perspective of monetary policy and studies whether endogenous producer entry and product variety generate optimal deviations from price stability in the long and the short run. We address this question in a dynamic, stochastic, general equilibrium model with imperfect price adjustment and study Ramsey-optimal monetary policy in a second-best environment in which lump-sum taxes are not available. Therefore, our paper contributes to a large literature, reviewed below, that seeks to describe optimal monetary policy in fully articulated, general-equilibrium models with nominal and real rigidities, using the tools of modern public finance (e.g. Khan, King, and Wolman, 2003, and Adao, Correia, and Teles, 2003). ${ }^{1}$

Producer entry in our model takes place subject to sunk costs in the expectation of future monopoly profits. On the consumer side, entry is motivated by preferences that exhibit a taste for variety; in particular, we assume that consumers have homothetic preferences over symmetric, individual products. Price adjustment is costly, as producers incur a quadratic adjustment cost to change their prices (Rotemberg, 1982). This generates a Phillips curve that relates the markup to producer price inflation. The central bank may try to use inflation to influence markups, in the long run and over the business cycle, with the goal of closing the inefficiency wedge between the marginal rate of consumption-leisure substitution and the marginal product of labor. Furthermore, when the benefit of variety to consumers and the market incentive for product creation are not aligned, an additional distortion occurs: If the benefit of variety exceeds the markup, there is too little entry, and vice versa (Bilbiie, Ghironi, and Melitz, 2008a). The central bank may use inflation - in the long run and/or over the business cycle - to align markups (which govern entry incentives) and benefit of variety. When preferences are such that the elasticity of substitution between varieties depends on their number, time-variation in the desired, flexible-price markup introduces a dynamic dimension to the distortions in labor supply and product creation by generating a misallocation

\footnotetext{
${ }^{1}$ Lucas and Stokey (1983) started off the literature on Ramsey-optimal fiscal and monetary policy. Chari, Christiano, and Kehoe (1991) study optimal fiscal and monetary policy under flexible prices and extend the model to include capital. An incomplete list of recent contributions in a variety of scenarios includes Arseneau and Chugh (2008), Chugh (2006), Schmitt-Grohé and Uribe (2004a,b), and Siu (2004).
} 
of resources across time and states of nature (Bilbiie, Ghironi, and Melitz, 2008a). The central bank can thus in principle use inflation over the business cycle to smooth the path of the markup over time. We study how these distortions and possible objectives for the central bank shape the optimal conduct of monetary policy.

Our results are twofold, pertaining to long-run and short-run inflation. Significant deviations from long-run price stability can be optimal, and their sign and magnitude depend on the balance of market incentives for entry and welfare benefit of variety. When the market outcome results in too much entry (the net markup is higher than the benefit of variety), the central bank uses its leverage over real activity by choosing a positive steady-state producer price inflation rate to erode the markup and reduce suboptimal entry. Long-run deflation occurs when the market provides too little entry, for it is deflation that increases markups and boosts entry in this case. Optimal longrun inflation is zero if and only if preferences feature constant elasticity of substitution (C.E.S.) in the form introduced by Dixit and Stiglitz (1977-henceforth, C.E.S.-D.S.). This preference specification is characterized by a perfect balancing of incentive for product creation and benefit of variety. Importantly, optimal deviations from long-run price stability generated by departing from this knife-edge scenario can be quantitatively significant: Depending on the value of the parameter that measures the benefit of variety, the optimal inflation rate ranges from an annualized 4 percent to an annualized -8 percent; these numbers are even larger under price indexation. Plausible preferences and parameter values justify the 2 percent target adopted by central banks throughout the industrialized world (see Table 1 in Schmitt-Grohé and Uribe, 2011, for a summary).

In the short run, however, we find that price stability (around a possibly non-zero optimal trend) is a robust policy prescription. We illustrate this result by plotting impulse responses of real and nominal variables to productivity shocks under the optimal policy and under stable prices, and showing that the differences between the two equilibria are insignificant. Under C.E.S.-D.S. preferences, this implies that the central bank does not attempt to use inflation (over the business cycle as in the long run) to close the constant gap between the marginal rate of consumption-leisure substitution and the marginal product of labor that generates inefficiency. With more general C.E.S. preferences that disentangle benefit of variety and market power, this implies that the central bank has no incentive to deviate from the optimal long-run inflation rate in an attempt to further close the (constant) inefficiency wedge between benefit of variety and market incentives for entry. Finally, with non-C.E.S. (exponential or translog) preferences, we find that the monetary authority makes no use of inflation over time to correct for the misallocation of resources across time and states that 
occurs with a time-varying flexible-price markup. This robust result of short-run price stability is consistent with standard tax smoothing arguments made in the dynamic public finance literature (see Golosov and Tsyvinski, 2006, for a review): The Ramsey planner tries to smooth inefficiency wedges over time, but this results in our framework in a path for its instrument (inflation) that is close to constant. ${ }^{2}$

We conclude our analysis by calculating the welfare costs (in units of steady-state consumption) of perfectly stabilizing prices in the long and in the short run, and we find that the cost of price stability can indeed be sizable, the more so, the more the benefit of variety deviates from the net markup. A decomposition of this welfare loss in a static component (due to the misalignment of benefit of variety and entry incentive) and a dynamic one (due to a time-varying flexible-price markup) indicates that the latter is negligible. Therefore, our conclusion is that the introduction of endogenous entry and more general preferences for variety than C.E.S.-D.S. can dramatically alter the long-run policy prescriptions obtained under fixed variety, but not the short-run implications.

Our results contribute to a large and growing literature on optimal monetary policy and inflation by studying a hitherto unexplored motive for non-zero optimal inflation. To isolate the contribution of the novel feature of our analysis (entry and variety), we abstract from other, well understood features that have been shown to result in optimal deviations from price stability. In particular, the presence of government spending has been shown to imply optimal deviations from price stability in a variety of economic environments and under different approaches to the optimal policy problem. This conclusion arises in the Ramsey-optimal policy exercises of Khan, King, and Wolman (2003), whose model features staggered pricing and monetary and real distortions, and Adão, Correia, and Teles (2003), whose model features predetermined prices. The same conclusion emerges from the linear-quadratic environment of Woodford (2003, Ch. 6.5), whose model features Calvo (1983) pricing and a distorted steady state (see also Benigno and Woodford, 2005). The first two papers also discuss the role of monetary distortions in shaping policy tradeoffs; Ireland (1996) had shown that the Friedman rule is optimal in a monetary model with preset prices, and this result extends to a variety of economic environments. In the absence of government spending and money demand distortions, however, price stability is optimal or at least close to optimal in these models: The monetary authority does not use inflation (a distortionary tax) to try to close the constant wedge

\footnotetext{
${ }^{2}$ This result is consistent with the analysis of Ramsey-optimal fiscal policy in Chugh and Ghironi (2009), in a flexible-price model similar to ours. There, the Ramsey planner chooses a smooth path for the tax rate on dividends, for the same reason. Indeed, inflation in our framework resembles an indirect tax on dividends (see Bilbiie, Ghironi, and Melitz, 2008a).
} 
between the marginal rate of consumption-leisure substitution and the marginal product of labor implied by monopolistic competition and endogenous labor supply. ${ }^{3}$ It is important to notice that even when optimal deviations from short-run price stability occur in the existing literature (e.g. in the presence of government spending or monetary distortions), the finding that price stability is the optimal long-run policy prescription is surprisingly robust across a wide range of economic environments. ${ }^{4}$ Indeed, this is a common theme of all the variations of the baseline model considered by Woodford (2003): "The optimal long-run inflation target is zero in this model, no matter how large the steady-state distortions may be" (p. 462, emphasis in original). Schmitt-Grohé and Uribe (2011) comprehensively review the existing literature on optimal inflation and conclude that "the observed inflation objectives of central banks pose a puzzle for monetary theory"; optimal long-run inflation is zero or very close to zero under a wide range of economic frictions, including incomplete taxation, the zero lower bound on nominal interest rates, downward rigidity in nominal wages, and the quality bias in measured inflation ${ }^{5}$. Thus, endogenous entry and product variety yield a policy implication that is largely new to the literature. Two recent contributions study reasons for deviating from long-run price stability that are complementary to ours: Weber (2011) emphasizes the role of a constant rate of growth in firm-specific productivity and finds that the optimal rate of long-run inflation is equal to the growth rate, and Wolman (2011) finds that slight deflation is optimal in a two-sector model in which there is a trend in relative prices.

This paper is not the first to study optimal monetary policy under endogenous entry. In two recent contributions, Bilbiie, Ghironi, and Melitz (2008b) and Bergin and Corsetti (2008) study models with endogenous entry and imperfect price adjustment (sticky prices as in Rotemberg, 1982, and one-period-ahead predetermined prices, respectively). Both papers conclude that stabilizing producer price inflation at zero in all periods is Pareto optimal in first-best environments in which lump-sum taxes are available to finance the subsidies (or taxes) needed to correct real distortions. Lewis (2010) studies optimal monetary policy in an economy with entry, a cash-in-advance constraint, and sticky wages. In her model, optimal inflation is used over the cycle to improve upon

\footnotetext{
${ }^{3}$ Woodford (2003) and Benigno and Woodford (2005) show that, when the steady state is distorted and the distortion is large (there are no lump sum taxes available to finance the subsidies needed to restore optimality), even a constant level of government spending will lead to optimal deviations from short-run price stability. A central bank that aims at stabilizing output and inflation around their efficient levels will face a tradeoff induced by productivity shocks that act like "cost-push" shocks in the Phillips curve when steady-state government spending is not zero.

${ }^{4}$ Thomas (2008) and Faia (2009) are two examples of models (incorporating search and matching frictions in the labor market) in which long-run price stability is optimal and short-run price stability is not. Erceg, Henderson, and Levin (2000) showed that deviations from short-run price stability are optimal when nominal wages are also sticky.

${ }^{5}$ Two popular theoretical justifications for deviations from long-run price stability are the zero lower bound (see e.g. Billi, 2011) and downward nominal wage rigidity (Kim and Ruge-Murcia, 2009). Schmitt-Grohé and Uribe's results imply that these distortions are not enough to generate quantitatively significant deviations from price stability.
} 
the flexible-wage response to shocks. In independent work, Faia (2010) uses a framework similar to ours (essentially, the Bilbiie, Ghironi, and Melitz, 2008b model), but with C.E.S.-D.S. preferences and oligopolistic competition, as well as government spending shocks. She finds that the Ramsey long-run prescription is "zero inflation"; however, in the short run, significant deviations from price stability are required for optimality. While apparently in stark contrast with our short-run findings, the difference can be explained by the absence of government spending from our framework since, as noted above, government spending by itself implies optimal deviations from short-run price stability. In order to isolate the potential role of entry and variety in generating deviations from price stability, our framework therefore abstracts from government spending altogether. ${ }^{6}$

When considering these studies in relation to the conduct of monetary policy in reality, one may wonder whether it is appropriate for central banks to have distortions in product variety in mind when determining their inflation targets. There are two reasons for an affirmative answer. First, to the extent that variety is important for aggregate fluctuations and long-run welfare, generating the optimal amount of variety is consistent with the policy objective of a welfare-maximizing equilibrium. Second, even if one may argue that optimal variety is best implemented by regulation policy, reality shows that regulators intervene in the economy only under exceptional circumstances to affect the behavior of the largest firms (for instance, Microsoft). "Blanket" instruments that affect all producers at all points in time (such as inflation) are thus better suited to induce the optimal equilibrium for the aggregate economy. More generally, the exercise of this paper is one of finding the optimal monetary policy, given a certain economic environment-very much like all studies of optimal monetary policy on which this paper builds - rather than a more general public finance exercise that would try to assess which is the best policy instrument to use in order to address a certain distortion. ${ }^{7}$

Since the key determinant of optimal long-run inflation in our model is the balance of markups and benefit of variety, we conclude by observing that our results point to the need for continued research on the determinants of markups and serious empirical investigation of the nature of preferences for variety. ${ }^{8}$

\footnotetext{
${ }^{6}$ Faia also shows that policy rules targeting markups or asset prices can improve (from a welfare standpoint) upon strict inflation targeting.

${ }^{7}$ See Correia, Nicolini, and Teles (2008) for an example of how, when both consumption and labor income taxes are available, the optimal policy (and the optimal allocation itself) do not even depend on the degree of nominal rigidity.

${ }^{8}$ While research on markups has already been extensive (see, for instance, Rotemberg and Woodford, 1999, and, more recently, Nekarda and Ramey, 2010), there is little empirical evidence on the benefit of variety to consumers. We use this limited evidence in discussing policy scenarios below.
} 
The rest of the paper is organized as follows. Section 2 outlines a sticky-price model with endogenous entry and general homothetic preferences for variety, drawing on Bilbiie, Ghironi, and Melitz (2007; 2008a,b). Section 3 discusses the distortions that occur when prices are flexible. Section 4 describes and solves the Ramsey-optimal policy problem. Section 5 derives the optimal policy prescriptions and their quantitative implications for inflation and real variables, distinguishing between the long run and the short run. Section 6 quantifies the welfare costs of fully stabilizing producer prices, rather than following optimal policy. Section 7 concludes.

\section{The Model}

\section{Household Preferences and the Intratemporal Consumption Choice}

We consider a cashless economy as in Woodford (2003). The economy is populated by a unit mass of atomistic, identical households. The representative household supplies $L_{t}$ hours of work in each period $t$ in a competitive labor market for the nominal wage rate $W_{t}$ and maximizes expected intertemporal utility $E_{t}\left[\sum_{s=t}^{\infty} \beta^{s-t} U\left(C_{s}, L_{s}\right)\right]$, where $C_{t}$ is consumption and $\beta \in(0,1)$ the subjective discount factor. The period utility function takes the form $U\left(C_{t}, L_{t}\right)=\ln C_{t}-h\left(L_{t}\right)$, where $h_{L}(L)>0, h_{L L}(L) \geq 0$, and $\varphi \equiv h_{L L}(L) L / h_{L}(L) \geq 0$ is the inverse Frisch elasticity of labor supply to wages (and the inverse intertemporal elasticity of substitution in labor supply).

At time $t$, the household consumes the basket of goods $C_{t}$, defined over a continuum of goods $\Omega$. At any given time $t$, only a subset of goods $\Omega_{t} \subset \Omega$ is available. Let $p_{t}(\omega)$ denote the nominal price of a good $\omega \in \Omega_{t}$. Our model can be solved for any parametrization of symmetric homothetic preferences. For any such preferences, there exists a well defined consumption index $C_{t}$ and an associated welfare-based price index $P_{t}$. The demand for an individual variety, $c_{t}(\omega)$, is then obtained as $c_{t}(\omega) d \omega=C_{t} \partial P_{t} / \partial p_{t}(\omega)$, where we use the conventional notation for quantities with a continuum of goods as flow values. ${ }^{9}$

Given the demand for an individual variety, $c_{t}(\omega)$, the symmetric elasticity of demand $-\theta$ (where $\theta$ measures the elasticity of substitution) is in general a function of the number $N_{t}$ of goods available (where $N_{t}$ is the mass of $\Omega_{t}$ ):

$$
\theta\left(N_{t}\right) \equiv-\frac{\partial c_{t}(\omega)}{\partial p_{t}(\omega)} \frac{p_{t}(\omega)}{c_{t}(\omega)}, \quad \text { for any symmetric variety } \omega
$$

\footnotetext{
${ }^{9}$ See the appendix of Bilbiie, Ghironi, and Melitz (2007) for more details.
} 
The benefit of additional product variety is described by the relative price $\rho$ :

$$
\rho_{t}(\omega)=\rho\left(N_{t}\right) \equiv \frac{p_{t}(\omega)}{P_{t}}, \quad \text { for any symmetric variety } \omega
$$

or, in elasticity form:

$$
\epsilon\left(N_{t}\right) \equiv \frac{\rho^{\prime}\left(N_{t}\right)}{\rho\left(N_{t}\right)} N_{t}
$$

Together, $\theta\left(N_{t}\right)$ and $\epsilon\left(N_{t}\right)$ completely characterize the effects of preferences in our model; explicit expressions can be obtained for these objects upon specifying functional forms for preferences, as will become clear in the discussion below.

\section{Firms}

There is a continuum of monopolistically competitive firms, each producing a different variety $\omega \in \Omega{ }^{10}$ Production requires only one factor, labor. Aggregate labor productivity is indexed by $Z_{t}$, which represents the effectiveness of one unit of labor. Productivity is exogenous and follows an $A R(1)$ process in percent deviation from its steady-state level. Output supplied by firm $\omega$ is $y_{t}(\omega)=Z_{t} l_{t}(\omega)$, where $l_{t}(\omega)$ is the firm's labor demand for productive purposes. The unit cost of production, in units of the consumption good $C_{t}$, is $w_{t} / Z_{t}$, where $w_{t} \equiv W_{t} / P_{t}$ is the real wage.

Prior to entry, firms face a sunk entry cost of $f_{E}$ effective labor units, equal to $w_{t} f_{E} / Z_{t}$ units of the consumption good. There are no fixed production costs. Hence, all firms that enter the economy produce in every period, until they are hit with a "death" shock, which occurs with probability $\delta \in(0,1)$ in every period.

Firms face nominal rigidity in the form of a quadratic cost of adjusting prices over time (Rotemberg, 1982). Specifically, the real cost (in units of the composite basket) of output-price inflation volatility around a steady-state level of inflation equal to 0 faced by firm $\omega$ is:

$$
\operatorname{pac}_{t}(\omega) \equiv \frac{\kappa}{2}\left(\frac{p_{t}(\omega)}{p_{t-1}(\omega)}-1\right)^{2} \frac{p_{t}(\omega)}{P_{t}} y_{t}^{D}(\omega), \quad \kappa \geq 0
$$

This expression is interpreted as the amount of marketing materials that the firm must purchase when implementing a price change. We assume that this basket has the same composition as the

\footnotetext{
${ }^{10}$ For convenience, we use the terms good and variety interchangeably. Note that the assumption that each firm produces a different variety implies that the number of goods available $N_{t}$ is also the number of producers in period $t$. We refer to individual producers as firms following the standard convention in the New Keynesian literature. However, a more general - and empirically relevant - interpretation is to think of productive units as product lines at firms whose boundaries we leave unspecified. See Bilbiie, Ghironi, and Melitz (2007) for more details.
} 
consumption basket. The cost of adjusting prices is proportional to the real revenue from output sales, $\left(p_{t}(\omega) / P_{t}\right) y_{t}^{D}(\omega)$, where $y_{t}^{D}(\omega)$ is firm $\omega$ 's output demand, to capture the idea that larger firms must purchase more materials when implementing a price change.

Firms face demand for their output from consumers and firms themselves when they change prices. In each period, there is a mass $N_{t}$ of firms producing and setting prices in the economy. When a new firm sets the price of its output for the first time, we appeal to symmetry across firms and interpret the $t-1$ price in the expression of the price adjustment cost for that firm as the notional price that the firm would have set at time $t-1$ if it had been producing in that period. An intuition for this simplifying assumption is that all firms (even those that are setting the price for the first time) must buy the bundle of goods $\operatorname{pac}_{t}(\omega)$ when implementing a price decision. ${ }^{11}$ It should be noted, however, that this assumption is entirely consistent both with the original Rotemberg (1982) setup and with our timing assumption below. Specifically, new entrants behave as the (constant number of) price setters do in Rotemberg's framework, where an initial condition for the individual price is dictated by nature. In our framework, new entrants at any time $t$ who start producing and setting prices at $t+1$ are subject to precisely the same assumption as price setters in Rotemberg's original setup. Moreover, the assumption that a new entrant, at the time of its first price setting decision, knows the average product price last period is consistent with the timing assumption that an entrant starts producing only one period after entry, hence being able to "learn" the average product price during the entry period. ${ }^{12}$

The total demand for the output of firm $\omega, y_{t}^{D}(\omega)$ is thus used for both consumption and paying the price adjustment cost, and it has elasticity $-\theta\left(N_{t}\right)$ :

$$
\frac{\partial\left[y_{t}^{D}(\omega) /\left(C_{t}+P A C_{t}\right)\right]}{\partial\left[p_{t}(\omega) / P_{t}\right]}=-\theta\left(N_{t}\right)
$$

where $P A C_{t} \equiv N_{t} p a c_{t}(\omega)$, and we used symmetry across firms in the definition of the aggregate demand of the consumption basket for price adjustment purposes $P A C_{t}$.

Since $\rho_{t}(\omega) \equiv p_{t}(\omega) / P_{t}$ is the real price of firm $\omega$ 's output, firm $\omega$ 's real profit in period $t$ (distributed to households as dividend) can be written as:

$$
d_{t}(\omega)=\rho_{t}(\omega) y_{t}^{D}(\omega)-w_{t} l_{t}(\omega)-\frac{\kappa}{2}\left(\frac{p_{t}(\omega)}{p_{t-1}(\omega)}-1\right)^{2} \rho_{t}(\omega) y_{t}^{D}(\omega)
$$

\footnotetext{
${ }^{11}$ As shown by Bilbiie, Ghironi, and Melitz (2008b), alternative specifications in which new producers take the first price setting decision without incurring a cost relative to a notional $t-1$ decision result in very similar dynamics to the benchmark setup for realistic rates of firm destruction $\delta$.

${ }^{12}$ Symmetry of the equilibrium will imply $p_{t-1}(\omega)=p_{t-1} \forall \omega$.
} 
The real value of the firm at time $t$ (in units of consumption) is the expected present discounted value of future profits from $t+1$ on, discounted with the household's stochastic discount factor (see below):

$$
v_{t}(\omega)=E_{t} \sum_{s=t+1}^{\infty} \Lambda_{t, s} d_{s}(\omega),
$$

where $\Lambda_{t, s} \equiv[\beta(1-\delta)]^{s-t} C_{t} / C_{s}$ is the discount factor applied by households to future profits from firm $\omega$ (which faces a probability $\delta$ of being hit with the "death" shock in each period).

At time $t$, firm $\omega$ chooses $l_{t}(\omega)$ and $p_{t}(\omega)$ to maximize $d_{t}(\omega)+v_{t}(\omega)$ subject to $y_{t}(\omega)=y_{t}^{D}(\omega)$, taking $w_{t}, P_{t}, C_{t}, P A C_{t}$, and $Z_{t}$ as given. Letting $\lambda_{t}(\omega)$ denote the Lagrange multiplier on the constraint $y_{t}(\omega)=y_{t}^{D}(\omega)$, the first-order condition with respect to $l_{t}(\omega)$ yields:

$$
\lambda_{t}(\omega)=\frac{w_{t}}{Z_{t}} .
$$

The shadow value of an extra unit of output is simply the firm's marginal cost, common across all firms in the economy.

The first-order condition with respect to $p_{t}(\omega)$ yields:

$$
p_{t}(\omega)=\mu_{t}(\omega) P_{t} \lambda_{t}(\omega) .
$$

Firm $\omega$ sets the price as a markup $\left(\mu_{t}(\omega)\right)$ over nominal marginal cost, where the markup $\mu_{t}(\omega)$ is given by

$$
\begin{aligned}
\mu_{t}(\omega) & \equiv \frac{\theta\left(N_{t}\right) y_{t}(\omega)}{\left[\theta\left(N_{t}\right)-1\right] y_{t}(\omega)\left[1-\frac{\kappa}{2}\left(\frac{p_{t}(\omega)}{p_{t-1}(\omega)}-1\right)^{2}\right]+\kappa \Upsilon_{t}}, \\
\Upsilon_{t} & \equiv y_{t}(\omega) \frac{p_{t}(\omega)}{p_{t-1}(\omega)}\left(\frac{p_{t}(\omega)}{p_{t-1}(\omega)}-1\right)-E_{t}\left[\Lambda_{t, t+1} y_{t+1}(\omega) \frac{P_{t}}{P_{t+1}}\left(\frac{p_{t+1}(\omega)}{p_{t}(\omega)}\right)^{2}\left(\frac{p_{t+1}(\omega)}{p_{t}(\omega)}-1\right)\right] .
\end{aligned}
$$

The markup reduces to $\theta\left(N_{t}\right) /\left[\theta\left(N_{t}\right)-1\right]$ in the absence of nominal rigidity $(\kappa=0)$.

\section{Firm Entry and Exit}

In every period, there is an unbounded mass of prospective entrants. These entrants are forward looking, and correctly anticipate their future expected profits $d_{t}(\omega)$ in every period as well as the probability $\delta$ (in every period) of incurring the exit-inducing shock. We assume that entrants at time $t$ only start producing at time $t+1$, which introduces a one-period time-to-build lag in the 
model. The exogenous exit shock occurs at the very end of the time period (after production and entry). A proportion $\delta$ of new entrants will therefore never produce. Prospective entrants in period $t$ compute their expected post-entry value given by the present discounted value of their expected stream of profits $v_{t}(\omega)$. This also represents the average value of incumbent firms after production has occurred (since both new entrants and incumbents then face the same probability $1-\delta$ of survival and production in the subsequent period). Entry occurs until firm value is equalized with the entry cost, leading to the free entry condition $v_{t}(\omega)=w_{t} f_{E} / Z_{t}$. This condition holds so long as the mass $N_{E, t}$ of entrants is positive. We assume that macroeconomic shocks are small enough for this condition to hold in every period. ${ }^{13}$ Finally, the timing of entry and production we have assumed implies that the number of producing firms during period $t$ is given by $N_{t}=(1-\delta)\left(N_{t-1}+N_{E, t-1}\right)$.

\section{Symmetric Firm Equilibrium}

In equilibrium, all firms make identical choices. Hence, $\lambda_{t}(\omega)=\lambda_{t}, p_{t}(\omega)=p_{t}, \mu_{t}(\omega)=\mu_{t}$, $\rho_{t}(\omega)=\rho_{t}, l_{t}(\omega)=l_{t}, y_{t}(\omega)=y_{t}, \operatorname{pac}_{t}(\omega)=\operatorname{pac}_{t}, d_{t}(\omega)=d_{t}$, and $v_{t}(\omega)=v_{t}$. The aggregate output of the consumption basket (used for consumption and to pay price adjustment costs) is

$$
Y_{t}^{C} \equiv C_{t}+P A C_{t}=N_{t} \rho_{t} y_{t}=N_{t} \rho_{t} Z_{t} l_{t}
$$

where $\rho_{t}=\rho\left(N_{t}\right)$ captures a "variety effect" that depends on the specification of preferences across varieties (see below).

Let $\pi_{t}$ denote inflation in producer prices: $\pi_{t} \equiv p_{t} / p_{t-1}-1$. Then, we can write:

$$
\mu_{t}=\frac{\theta\left(N_{t}\right)}{\left[\theta\left(N_{t}\right)-1\right]\left(1-\frac{\kappa}{2} \pi_{t}^{2}\right)+\kappa\left\{\left(1+\pi_{t}\right) \pi_{t}-\beta(1-\delta) E_{t}\left[\frac{C_{t}}{C_{t+1}} \frac{N_{t}}{N_{t+1}} \frac{Y_{t+1}^{C}}{Y_{t}^{C}}\left(1+\pi_{t+1}\right) \pi_{t+1}\right]\right\}}
$$

This can be simplified further by noting that $P A C_{t}=\kappa \pi_{t}^{2} Y_{t}^{C} / 2$, so that $C_{t}=\left(1-\kappa \pi_{t}^{2} / 2\right) Y_{t}^{C}$, to obtain:

$$
\mu_{t}=\frac{\theta\left(N_{t}\right)}{\left[\theta\left(N_{t}\right)-1\right]\left(1-\frac{\kappa}{2} \pi_{t}^{2}\right)+\kappa\left\{\left(1+\pi_{t}\right) \pi_{t}-\beta(1-\delta) E_{t}\left[\frac{1-\frac{\kappa}{2} \pi_{t}^{2}}{1-\frac{\kappa}{2} \pi_{t+1}^{2}} \frac{N_{t}}{N_{t+1}}\left(1+\pi_{t+1}\right) \pi_{t+1}\right]\right\}}
$$

This equation is the non-linear Phillips curve relation in our model. Bilbiie, Ghironi, and Melitz

\footnotetext{
${ }^{13}$ If $v_{t}(\omega)<w_{t} f_{E} / Z_{t}$, prospective entrants will not be willing to incur the sunk entry cost, resulting in zero entry.
} 
(2008b) show that its log-linear version (around a steady state with zero inflation) reduces to a standard New Keynesian Phillips curve augmented for the effect of changes in the number of available product varieties.

\section{Household Budget Constraint, Saving, and Labor Supply}

Households hold two types of assets: shares in a mutual fund of firms and bonds. Let $x_{t}$ be the share in the mutual fund of firms held by the representative household entering period $t$. The mutual fund pays a total profit in each period (in units of currency) that is equal to the total profit of all firms that produce in that period, $P_{t} N_{t} d_{t}$. During period $t$, the representative household buys $x_{t+1}$ shares in a mutual fund of $N_{t}+N_{E, t}$ firms (those already operating at time $t$ and the new entrants). Only a $1-\delta$ fraction of these firms will produce and pay dividends at time $t+1$. Since the household does not know which firms will be hit by the exogenous exit shock $\delta$ at the very end of period $t$, it finances the continuing operation of all pre-existing firms and all new entrants during period $t$. The date $t$ price of a claim to the future profit stream of the mutual fund of $N_{t}+N_{E, t}$ firms is equal to the average nominal price of claims to future profits of home firms, $V_{t} \equiv P_{t} v_{t}$.

The household enters period $t$ with nominal bond holdings $B_{N, t}$ and mutual fund share holdings $x_{t}$. It receives gross interest income on bond holdings, dividend income on mutual fund share holdings and the value of selling its initial share position, and labor income. The household allocates these resources between purchases of bonds and shares to be carried into next period and consumption. The period budget constraint (in units of currency) is:

$$
B_{N, t+1}+V_{t}\left(N_{t}+N_{E, t}\right) x_{t+1}+P_{t} C_{t}=\left(1+i_{t-1}\right) B_{N, t}+\left(D_{t}+V_{t}\right) N_{t} x_{t}+W_{t} L_{t},
$$

where $i_{t-1}$ denotes the nominal interest rate on holdings of bonds between $t-1$ and $t$, and $D_{t}$ denotes nominal dividends $\left(D_{t} \equiv P_{t} d_{t}\right)$. Dividing both sides by $P_{t}$ and denoting holdings of bonds in units of consumption with $B_{t+1} \equiv B_{N, t+1} / P_{t}$, we can write

$$
B_{t+1}+v_{t}\left(N_{t}+N_{E, t}\right) x_{t+1}+C_{t}=\left(1+r_{t}\right) B_{t}+\left(d_{t}+v_{t}\right) N_{t} x_{t}+w_{t} L_{t}
$$

where $1+r_{t}$ is the gross, consumption-based, real interest rate on holdings of bonds between $t-1$ and $t$, defined by $1+r_{t} \equiv\left(1+i_{t-1}\right) /\left(1+\pi_{t}^{C}\right)$, with $\pi_{t}^{C} \equiv P_{t} / P_{t-1}-1$. The household maximizes its expected intertemporal utility subject to this budget constraint. 
The Euler equations for bond and share holdings are:

$$
\left(C_{t}\right)^{-1}=\beta E_{t}\left[\frac{1+i_{t}}{1+\pi_{t+1}^{C}}\left(C_{t+1}\right)^{-1}\right] \quad \text { and } \quad v_{t}=\beta(1-\delta) E_{t}\left[\left(\frac{C_{t+1}}{C_{t}}\right)^{-1}\left(v_{t+1}+d_{t+1}\right)\right] \text {. }
$$

As expected, forward iteration of the equation for share holdings and absence of speculative bubbles yield the asset price solution in equation $(2) \cdot{ }^{14}$

The first-order condition for the optimal choice of labor effort requires that the marginal disutility of labor be equal to the marginal utility from consuming the real wage received for an additional unit of labor:

$$
h_{L}\left(L_{t}\right)=\frac{w_{t}}{C_{t}}
$$

\section{Aggregate Accounting and Equilibrium}

Aggregating the budget constraint (4) across households and imposing the equilibrium conditions $B_{t+1}=B_{t}=0$ and $x_{t+1}=x_{t}=1, \forall t$, yields the aggregate accounting identity $Y_{t} \equiv C_{t}+N_{E, t} v_{t}=$ $w_{t} L_{t}+N_{t} d_{t}$, where we defined GDP, $Y_{t}$ : Consumption plus investment (in new firms) must be equal to income (labor income plus dividend income).

Labor market equilibrium requires $N_{t} l_{t}+N_{E, t} f_{E} / Z_{t}=L_{t}$ : The total amount of labor used in production and to set up the new entrants' plants must equal aggregate labor supply. (Of course, this condition is redundant once equilibrium in goods and asset markets is imposed.) The equilibrium conditions of our benchmark model are summarized in Table 1. The model is closed by specifying monetary policy conduct - in Table 1, there are 12 equations and 13 endogenous variables. Bilbiie, Ghironi, and Melitz (2008b) analyze the case where monetary policy follows a simple Taylor rule, as well as optimal monetary policy in a first-best environment. Here, we study optimal policy using the Ramsey approach, following a vast literature on optimal policy in secondbest environments. Before doing that, we outline the particular preference specifications that we will use as examples and discuss a measurement issue that arises in this class of models. We then review the sources of inefficiency (distortions) that are present even when all firms set their prices freely.

\footnotetext{
${ }^{14}$ We omit the transversality conditions for bonds and shares that must be satisfied to ensure optimality.
} 
Table 1. Benchmark Model, Summary

\begin{tabular}{ll}
\hline Pricing & $\rho_{t}=\mu_{t} \frac{w_{t}}{Z_{t}}$ \\
\hline Markup & $\mu_{t}=\frac{\rho^{\prime}}{\left[\theta\left(N_{t}\right)-1\right]\left(1-\frac{\kappa}{2} \pi_{t}^{2}\right)+\kappa\left\{\left(1+\pi_{t}\right) \pi_{t}-\beta(1-\delta) E_{t}\left[\frac{C_{t}}{C_{t+1}} \frac{N_{t}}{N_{t+1}} \frac{Y_{t+1}^{C}}{Y_{t}^{C}}\left(1+\pi_{t+1}\right) \pi_{t+1}\right]\right\}}$ \\
\hline Variety effect & $\rho_{t}=\rho\left(N_{t}\right)$ \\
\hline Profits & $d_{t}=\left(1-\frac{\theta\left(N_{t}\right)-1}{\theta\left(N_{t}\right)}-\frac{\kappa}{2} \pi_{t}^{2}\right) \frac{Y_{t}^{C}}{N_{t}}$ \\
\hline Free entry & $v_{t}=w_{t} \frac{f_{E}}{Z_{t}}$ \\
\hline Number of firms & $N_{t}=(1-\delta)\left(N_{t-1}+N_{E, t-1}\right)$ \\
\hline Intratemporal optimality & $h_{L}\left(L_{t}\right)=\frac{w_{t}}{C_{t}}$ \\
\hline Euler equation (shares) & $v_{t}=\beta(1-\delta) E_{t}\left[\left(\frac{C_{t+1}}{C_{t}}\right)^{-1}\left(v_{t+1}+d_{t+1}\right)\right]$ \\
\hline Euler equation (bonds) & $\left(C_{t}\right)^{-1}=\beta E_{t}\left[\frac{1+i_{t}}{1+\pi_{t+1}^{C}}\left(C_{t+1}\right)^{-1}\right]$ \\
\hline Output of consumption sector & $Y_{t}^{C}=\left(1-\frac{\kappa}{2} \pi_{t}^{2}\right)^{-1} C_{t}$ \\
\hline Aggregate accounting & $C_{t}+N_{E, t} v_{t}=w_{t} L_{t}+N_{t} d_{t}$ \\
\hline CPI inflation & $\frac{1+\pi_{t}}{1+\pi_{t}^{C}}=\frac{\rho_{t}}{\rho_{t-1}}$ \\
\hline
\end{tabular}

\section{Preference Specifications and Flexible-Price Markups}

We consider four alternative preference specifications as special cases for illustrative purposes below. Here, we discuss the implications of these preferences for the welfare benefit of variety and the desired, flexible-price markups, obtained if all individual producers can adjust their prices freely in the flexible-price equilibrium, which we denote with a star.

The first preference specification features a constant elasticity of substitution between goods as in Dixit and Stiglitz (1977). For these C.E.S. preferences, the consumption aggregator is $C_{t}=\left(\int_{\omega \in \Omega} c_{t}(\omega)^{\theta-1 / \theta} d \omega\right)^{\theta /(\theta-1)}$, where $\theta>1$ is the symmetric elasticity of substitution across goods. The consumption-based price index is then $P_{t}=\left(\int_{\omega \in \Omega_{t}} p_{t}(\omega)^{1-\theta} d \omega\right)^{1 /(1-\theta)}$, and the household's demand for each individual good $\omega$ is $c_{t}(\omega)=\left(p_{t}(\omega) / P_{t}\right)^{-\theta} C_{t}$. It follows that the flexibleprice markup and the benefit of variety are independent of the number of goods: $\mu^{*}\left(N_{t}\right)-1=$ $\epsilon^{*}\left(N_{t}\right)=\epsilon=1 /(\theta-1)$. The second specification is the C.E.S. variant with generalized love of variety introduced by the working paper version of Dixit and Stiglitz (1977) and studied by Benassy (1996), which disentangles monopoly power (measured by the net markup 1/ $(\theta-1)$ ) and consumer 
love for variety, captured by a constant parameter $\epsilon>0$. With this specification (labelled "general C.E.S." henceforth), the consumption basket is $C_{t}=\left(N_{t}\right)^{\epsilon-\frac{1}{\theta-1}}\left(\int_{\omega \in \Omega} c_{t}(\omega)^{\theta-1 / \theta} d \omega\right)^{\theta /(\theta-1)}$. The third preference specification features exponential love-of-variety (we call it "exponential" for short) and is in some sense just the opposite of the previous: the elasticity of substitution is not constant (because of demand-side pricing complementarities), but the benefit of variety is equal to the net markup. Specifically, the elasticity of substitution is $\theta^{*}\left(N_{t}\right)=1+\alpha N_{t}$, where $\alpha>0$ is a free parameter, and the relative price is given by $\rho^{*}\left(N_{t}\right)=e^{-\frac{1}{\alpha N_{t}}}$; hence, the benefit of variety and the markup are, respectively: $\epsilon^{*}\left(N_{t}\right)=\mu^{*}\left(N_{t}\right)-1=1 / \alpha N_{t}$. As $N_{t}$ increases, goods become closer substitutes, and the elasticity of substitution increases. If goods are closer substitutes, then the markup $\mu^{*}\left(N_{t}\right)$ and the benefit of additional varieties in elasticity form $\left(\epsilon^{*}\left(N_{t}\right)\right)$ must decrease; ${ }^{15}$ for this specific functional form, the markup and benefit of variety decrease by the same amount when $N_{t}$ increases. Finally, the fourth preference specification uses the translog expenditure function proposed by Feenstra (2003). For this specification, the symmetric price elasticity of demand is $1+\sigma N_{t}$, with $\sigma>0$. In contrast to the previous specification, the change in $\epsilon^{*}\left(N_{t}\right)$ is only half the change in the net markup generated by an increase in the number of producers. Table 2 summarizes the expressions for markup, relative price, and benefit of variety in elasticity form for each preference specification.

Table 2. Four Preference Specifications

\begin{tabular}{llll}
\hline \hline C.E.S.-D.S. & General C.E.S. & Exponential & Translog \\
\hline$\mu^{*}=\frac{\theta}{\theta-1}$ & $\mu^{*}=\frac{\theta}{\theta-1}$ & $\mu^{*}\left(N_{t}\right)=\frac{\theta^{*}\left(N_{t}\right)}{\theta^{*}\left(N_{t}\right)-1}=1+\frac{1}{\alpha N_{t}}$ & $\mu^{*}\left(N_{t}\right)=\frac{\theta^{*}\left(N_{t}\right)}{\theta^{*}\left(N_{t}\right)-1}=1+\frac{1}{\sigma N_{t}}$ \\
\hline$\rho^{*}\left(N_{t}\right)=\left(N_{t}\right)^{\frac{1}{\theta-1}}$ & $\rho^{*}\left(N_{t}\right)=\left(N_{t}\right)^{\epsilon}$ & $\rho^{*}\left(N_{t}\right)=e^{-\frac{1}{\alpha N_{t}}}$ & $\rho^{*}\left(N_{t}\right)=e^{-\frac{1}{2} \frac{N-N_{t}}{\sigma N N_{t}}}, \tilde{N} \equiv \operatorname{Mass}(\Omega)$ \\
\hline$\epsilon^{*}\left(N_{t}\right)=\mu^{*}-1$ & $\epsilon^{*}\left(N_{t}\right)=\epsilon$ & $\epsilon^{*}\left(N_{t}\right)=\frac{1}{\alpha N_{t}}=\mu^{*}\left(N_{t}\right)-1$ & $\epsilon^{*}\left(N_{t}\right)=\frac{1}{2 \sigma N_{t}}=\frac{1}{2}\left(\mu^{*}\left(N_{t}\right)-1\right)$ \\
\hline
\end{tabular}

\section{A Measurement Issue: Consumer versus Producer Price Inflation}

As argued at length in Bilbiie, Ghironi, and Melitz (2007 and 2008b), a measurement issue applies to any model with product variety: Empirically relevant variables - as opposed to welfare-consistent concepts - net out the effect of changes in the range of available products. The reason is that construction of consumer price index (CPI) data by statistical agencies does not adjust for availability of new products as in the welfare-consistent price index. Furthermore, adjustment for variety, when

\footnotetext{
${ }^{15}$ This property for the markup occurs whenever the price elasticity of residual demand decreases with quantity consumed along the residual demand curve.
} 
it happens, certainly neither happens at the frequency represented by periods in our model, nor using one of the specific functional forms for preferences that our model assumes. Mismeasurement of the CPI, and more specifically, the bias induced by not accounting for new goods, has been the subject of much research starting with the Boskin Commission Report (Boskin et al, 1996). In particular, the commission found that the CPI was subject to an upward measurement bias of 1.2 percent on average (estimates ranging from 0.8 to 1.6 percent), half of which was due to not accounting for the introduction of new (or better-quality) goods; Gordon (2000, 2006) discusses why these estimates are indeed very conservative, and why the bias from not accounting for new goods may be larger. More recently, Broda and Weinstein (2010) also document the sizable upward bias induced in measured CPI by not accounting for new varieties: The CPI is on average 0.8 percentage points per year higher than a cost-of-living index that takes product turnover into account.

An implication of this measurement issue for our model is that the "true" welfare-based CPI of our model is not observable in the data or, conversely, that the observed, measured CPI is closer to the producer price index (PPI) of our model (the average price of a product) $p_{t}$ than $P_{t} .{ }^{16}$ Since the PPI is the price index in the model available to a central bank trying to measure inflation, all of our normative discussion below will be cast in terms of this observable variable: Consequently, we will use "inflation" to refer to "PPI inflation" below.

\section{Sources of Inefficiency in the Flexible-Price Equilibrium}

Bilbiie, Ghironi, and Melitz (2008b) and Bergin and Corsetti (2008) show that optimal monetary policy always seeks to stabilize producer prices perfectly in a first-best environment (where lumpsum taxes/transfers are available to finance any optimal subsidies/taxes used to correct distortions that arise under flexible prices). The question that we address in this paper is: Would a Ramsey planner that operates in a second-best environment (where such lump-sum taxes are not available) choose non-zero inflation in the long run (in steady state) and over the business cycle?

Before we delve into this question, it is useful to review the sources of distortions that can make the flexible-price equilibrium (obtained when $\kappa=0$ ) inefficient in our model; A detailed discussion of the inefficiencies associated with monopolistic competition and entry in this framework is provided by Bilbiie, Ghironi, and Melitz (2008a).

\footnotetext{
${ }^{16}$ For this reason, when investigating the properties of their model in relation to the data, Bilbiie, Ghironi, and Melitz (2007 and 2008b) focus on real variables deflated by a data-consistent price index: For any variable $X_{t}$ in units of the consumption basket, its data-consistent counterpart is obtained as $X_{R, t} \equiv P_{t} X_{t} / p_{t}=X_{t} / \rho_{t}=X_{t} / \rho\left(N_{t}\right)$.
} 
The flexible-price model features two margins of adjustment: a static, intratemporal margin (captured by the optimality condition for labor effort) and a dynamic, intertemporal margin (captured by the Euler equation for the number of products). Associated with each of these margins is an inefficiency wedge relative to the corresponding optimality condition for the social planning problem. There are three distortions that impact these two margins and the associated wedges:

Distortion 1. The first distortion affects the intratemporal labor optimality condition: With elastic labor supply, and consumption goods priced at a markup over marginal cost, the household "buys" an inefficiently high amount of the cheaper good (leisure, which is not priced at a markup), and so it ends up working and consuming too little. This is true in models with endogenous variety as in models with fixed variety. The inefficiency wedge in labor optimality can be constant (as under C.E.S. preferences) or time-varying (as under exponential or translog preferences). We refer to this distortion as the "labor distortion."

Distortion 2. The second distortion operates through the intertemporal product creation margin: When the welfare benefit of variety $\epsilon^{*}\left(N_{t}\right)$ and the net markup $\mu^{*}\left(N_{t}\right)-1$ (which measures the profit incentive for firms to enter the market) are not aligned, entry is inefficient from a social standpoint. When, for instance, the benefit of variety is low compared to the desired markup $\left(\epsilon^{*}(N t)<\mu^{*}\left(N_{t}\right)-1\right)$, the consumer surplus of creating a new variety is lower than the profit signal received by a potential entrant; the resulting entry is therefore too high, and the size of the distortion is governed by the difference between the desired net markup and the benefit of variety. The opposite holds - the level of entry is inefficiently low-when $\epsilon^{*}(N t)>\mu^{*}\left(N_{t}\right)-1$. We refer to this distortion as the "static entry distortion" below, where "entry" refers to the fact that the distortion affects an intertemporal margin and "static" highlights the fact that this distortion - a within-the-period misalignment of benefit of variety and markup - still operates if we are in a static model and/or in steady state, and for C.E.S. preferences for which Distortion 3 below disappears.

Distortion 3. The third distortion also operates through the intertemporal product creation margin, combining with Distortion 2 to determine the inefficiency wedge in this margin relative to the social (Pareto) optimum: Variations in desired markups over time (induced by changes in the elasticity of substitution as the product space changes) introduce an additional discrepancyequal to equal to the ratio $\mu^{*}\left(N_{t}\right) / \mu^{*}\left(N_{t+1}\right)$-between the "private" (competitive equilibrium) and "social" (Pareto optimum) return to a new variety. When there is entry, the future 
markup is lower than the current one, and this ratio increases, generating an additional inefficient reallocation of resources to entry in the current period. We refer to this distortion as the "dynamic entry distortion" below, where "entry" again captures its relevance to the model's intertemporal margin and associated wedge, and "dynamic" refers to the fact that this distortion operates only with preferences that allow for time-varying markups and, therefore, misalignment of markups across time and states.

Note that distortions 2 and 3 disappear when preferences are of the C.E.S.-DS form. In this case, the market economy achieves efficiency along the product creation margin.

The remarkable feature of all three distortions listed above is that they depend on the markup. With sticky prices, a Phillips curve relates markups with current and expected inflation; the central bank can therefore attempt to correct these distortions by using the level and intertemporal path of inflation to affect the level and intertemporal path of markups. In the plain vanilla sticky price model with C.E.S.-DS preferences and labor as the only factor of production, optimal policy refrains from using inflation to affect the average level of the markup and pursues price stability over the cycle to smooth the dynamics of the labor wedge (keeping it constant) by keeping the markup constant.

In this paper, we study the interaction of the flexible-price distortions above with the distortion implied by sticky prices in shaping Ramsey-optimal monetary policy in a second-best environment ${ }^{17}$. The question we started this section with can thus be re-stated as follows: Will a Ramsey planner use non-zero inflation (and so trade off some of the costs associated with it) in order to close the inefficiency wedges reviewed above, i.e., minimize the gap between marginal rate of substitution and transformation between consumption and labor, bring the profit incentives for firm entry and product creation closer to the benefit of variety to consumers, and/or smooth the intertemporal path of the markup?

\section{Ramsey-Optimal Monetary Policy and Endogenous Entry and Product Variety}

Before discussing the solution to our policy problem, it is useful to recall the benchmark results from the plain vanilla New Keynesian model with fixed variety (see for instance Woodford, 2003; Benigno and Woodford, 2005; and Woodford, 2011). In the most basic version of that framework,

\footnotetext{
${ }^{17}$ Bilbiie, Ghironi, and Melitz (2008a) study first-best fiscal policy that can decentralize the Pareto optimum, while Chugh and Ghironi (2009) study Ramsey-optimal fiscal policy in a second-best environment.
} 
inefficiency is due to the sticky-price distortion and the labor distortion (elastic labor and monopolistic competition). But - in the simplest version of the model in which no "cost-push" shocks are present - the welfare costs of inflation outweigh the potential benefits obtained by (even slight) variations in inflation that would lead to markup erosion and improve the labor wedge; hence, inflation is optimally not used. This is a standard-second best argument that holds regardless of the value of labor supply elasticity. While the result holds exactly in the simplest model, it has been shown (as reviewed in the Introduction) to be robust to the introduction of other frictions.

In the model with endogenous entry and product variety summarized in Table 1, we assume that the central bank chooses the optimal paths of all 13 endogenous variables that maximize the present discounted value of household utility, taking as constraints the 12 private agents' decision rules. Adding one Lagrange multiplier on each constraint, one obtains a system of 25 equations (12 private agents' decision rules and 13 first-order conditions) and 25 unknowns (13 original variables and 12 Lagrange multipliers). The resulting system can be solved numerically by standard perturbation methods.

In order to build intuition for the results that we will obtain numerically, we seek to obtain analytical results whenever possible. To that end, note that the problem can be greatly simplified as follows. First, since the nominal interest rate only enters the Euler equation for bonds, the problem can be regarded as one where the central bank (the Ramsey planner) chooses the allocation directly, and once the paths of consumption and CPI inflation are known, the path of the interest rate consistent with optimality is uniquely determined by the Euler equation. Similar reasoning and repeated substitutions of all the static equilibrium conditions into the three dynamic ones (the Phillips curve, the law of motion for variety, and the Euler equation for shares) allow us to reduce the model to the three-equation system in Table 3 , where $L_{C, t}$ denotes the total amount of labor used in production of existing goods $L_{C, t} \equiv N_{t} l_{t} .{ }^{18}$

Table 3. Reduced Model, Summary

$\overline{N_{t}=(1-\delta)\left(N_{t-1}+\frac{\left(L_{t}-L_{C, t}\right) Z_{t}}{f_{E}}\right)}$
$\frac{\theta\left(N_{t}\right)-1+\kappa\left\{\frac{\left(1+\pi_{t}\right) \pi_{t}}{1-\frac{\kappa}{2} \pi_{t}^{2}}-\beta(1-\delta) E_{t}\left[\frac{\left(1+\pi_{t+1}\right) \pi_{t+1}}{1-\frac{\kappa}{2} \pi_{t+1}^{2}} \frac{N_{t}}{N_{t+1}}\right]\right\}=\theta\left(N_{t}\right) L_{C, t} h_{L}\left(L_{t}\right)}{h_{L}\left(L_{t}\right) \frac{f_{E}}{Z_{t}}=\beta(1-\delta) E_{t}\left[\left(h_{L}\left(L_{t+1}\right) \frac{f_{E}}{Z_{t+1}}+\frac{1-L_{C, t+1} h_{L}\left(L_{t+1}\right)}{N_{t+1}}\right)\right]}$

Therefore, the Ramsey planner chooses total labor, producer price inflation, labor allocated to

\footnotetext{
${ }^{18}$ This requires using also $C_{t}=\left(1-\frac{\kappa}{2} \pi_{t}^{2}\right) Z_{t} \rho\left(N_{t}\right) L_{C, t}$, which is implied by aggregate accounting.
} 
the consumption sector, and the number of firms to maximize the following Lagrangian (where $\eta_{j, t}$ is the Lagrange multiplier on constraint $j$ in Table 3):

$$
\max _{L_{t}, \pi_{t}, L_{C, t}, N_{t+1}} E_{0} \sum_{t=0}^{\infty} \beta^{t}\left\{\ln \left[\left(1-\frac{\kappa}{2} \pi_{t}^{2}\right) Z_{t} \rho\left(N_{t}\right) L_{C, t}\right]-h\left(L_{t}\right)+\eta_{1, t}\left[N_{t+1}-(1-\delta)\left(N_{t}+\frac{\left(L_{t}-L_{t}^{C}\right) Z_{t}}{f_{E}}\right)\right]\right.
$$

$$
\begin{aligned}
& +\eta_{2, t}\left[\left(1-\theta\left(N_{t}\right)\right)\left(1-\frac{\kappa}{2} \pi_{t}^{2}\right)+\theta\left(N_{t}\right)\left(1-\frac{\kappa}{2} \pi_{t}^{2}\right) L_{C, t} h_{L}\left(L_{t}\right)-\kappa \pi_{t}\left(1+\pi_{t}\right)+\right. \\
& \left.+\beta(1-\delta) \kappa \pi_{t+1}\left(1+\pi_{t+1}\right) \frac{N_{t}}{N_{t+1}} \frac{1-\frac{\kappa}{2} \pi_{t}^{2}}{1-\frac{\kappa}{2} \pi_{t+1}^{2}}\right]+ \\
& \left.+\eta_{3, t}\left[h_{L}\left(L_{t}\right) \frac{f_{E}}{Z_{t}}-\beta(1-\delta)\left(h_{L}\left(L_{t+1}\right) \frac{f_{E}}{Z_{t+1}}+\frac{1-L_{C, t+1} h_{L}\left(L_{t+1}\right)}{N_{t+1}}\right)\right]\right\} .
\end{aligned}
$$

We present the first-order conditions of this problem in Appendix A, where we also prove the following result analytically.

Proposition 1 In a model with endogenous entry, homothetic preferences for variety, elastic labor, and quadratic price adjustment costs, optimal inflation in the Ramsey equilibrium is zero in steady state only if preferences are such that the benefit of variety is equal to the desired steady-state (net) markup:

$$
\epsilon(N)=\frac{1}{\theta(N)-1}
$$

\section{Proof. See Appendix A.}

It is worth emphasizing that zero long-run inflation is optimal (as long as the condition (6) holds) regardless of labor supply elasticity. In other words, the planner does not use her distortionary instrument (inflation) to correct the labor supply distortion in a standard second best fashion. The introduction of firm entry and endogenous product variety in an environment with C.E.S.D.S. preferences does not change the conclusions obtained in the simplest, fixed-variety model. Intuitively, since the product creation margin is efficient by virtue of the balancing of the benefit of variety with the monopoly profit incentive for entry, and the planner was already not using inflation in the fixed-variety case, endogenous entry does not give the planner any additional incentive to resort to this distortionary instrument.

When the condition (6) does not hold, i.e. when entry is distorted by the misalignment of markup and benefit of variety (the static entry distortion operates), a non-zero optimal long-run rate of inflation may emerge: Long-run inflation affects the steady-state markup and can be used by the central bank to close the gap between the profit incentive for firm entry (the steady-state 
markup) and the benefit of variety for consumers $(\epsilon)$. In doing so, the central bank must weigh the benefits of this policy against the welfare costs of inflation. To understand this trade-off, note that our model's long-run Phillips curve (LRPC), i.e. the relationship between steady-state net markup and steady-state inflation (under the assumption $\theta(N)=\theta$ ), is given by:

$$
L R P C: \mu(\pi)-1=\frac{\theta}{(\theta-1)\left(1-\frac{\kappa}{2} \pi^{2}\right)+\kappa \frac{r+\delta}{1+r}(1+\pi) \pi}-1
$$

This schedule is represented by the curve labelled LRPC in Figure 1, plotted against three values of the benefit of variety $\epsilon$, represented by the vertical dash-dotted lines: lower than, equal to and higher than the desired, flexible-price steady-state markup, respectively. The value $\underline{\pi}$ corresponds to the level of inflation that attains the lowest possible value of the markup $(\underline{\mu}) .{ }^{19}$ The knife-edge case for which Proposition 1 holds $(\epsilon=1 /(\theta-1))$ is obtained when the vertical line representing the benefit of variety intersects the markup curve at zero inflation. More generally, the problem of the monetary authority is to pick a long-run inflation rate corresponding to a point on the LRPC schedule that minimizes the gap between the steady-state markup $\mu(\pi)-1$ and the benefit of variety $\epsilon$, taking into account the welfare costs of generating inflation.

\footnotetext{
${ }^{19}$ Analytically, $\underline{\pi}=(r+\delta) /[(\theta-1)(1+r)-2(r+\delta)]$, which is positive for empirically plausible parameter values. Note that the curve in (7) has another, upper branch (not plotted) for positive inflation rates only; we ignore that branch because, with quadratic costs of inflation, inflation rates higher than $\underline{\pi}$ will never be chosen by an optimizing central bank.
} 


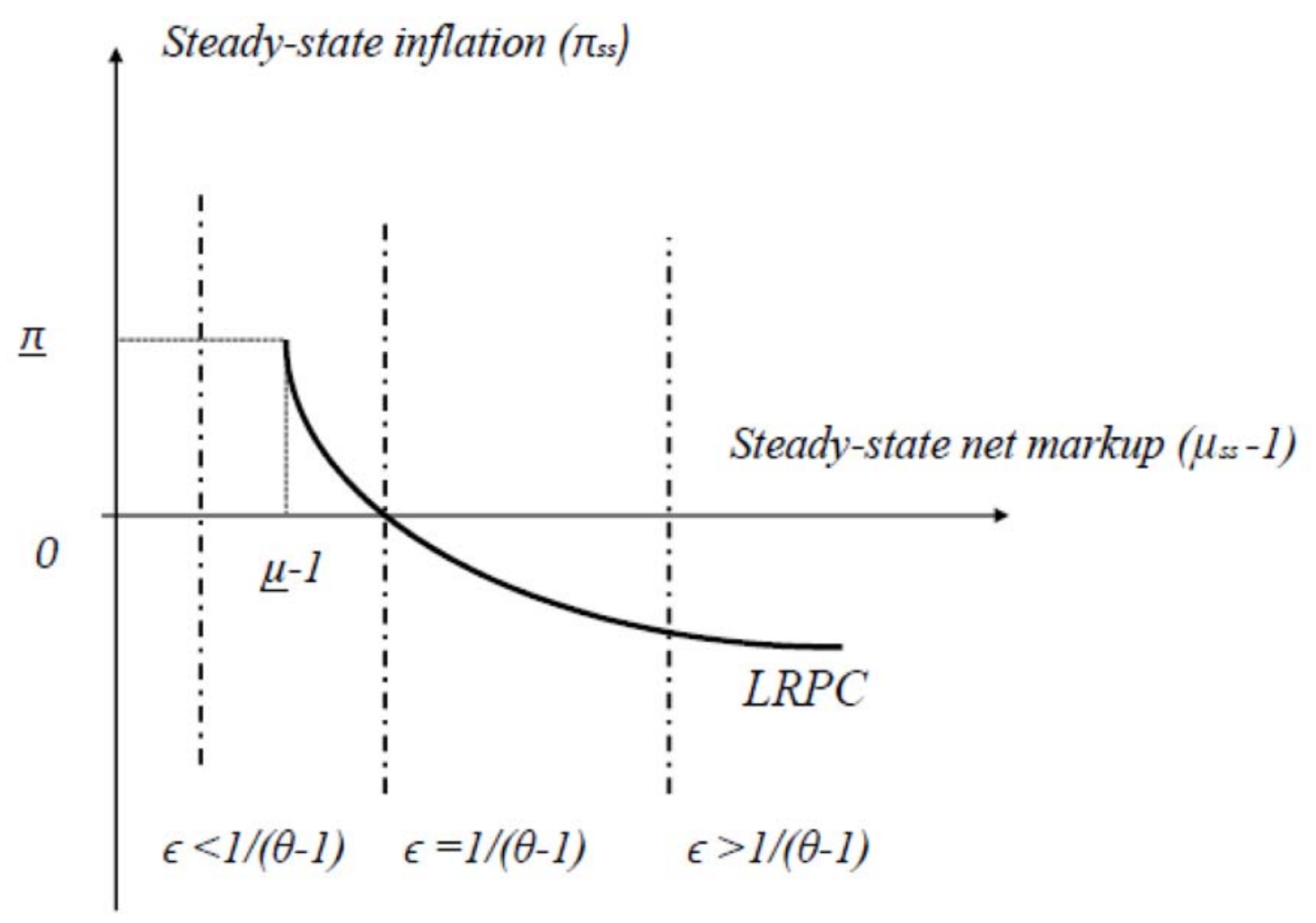

Figure 1: The Long-run Phillips curve.

When the benefit of variety is always lower than the net markup $(\epsilon<1 /(\theta-1))$, there is always too much entry in the monopolistically competitive equilibrium. The central bank cannot close this gap perfectly, but it can use inflation to minimize it by choosing the value of inflation that minimizes the steady-state markup and hence reduces entry. Using inflation entails welfare costs, though, so the optimal value of inflation will balance these costs with the benefit obtained from moving closer to the lower markup level (measured roughly by the distance between the LRPC and the leftmost vertical line in the figure, $\epsilon<1 /(\theta-1))$. When the benefit of variety is higher than the lowest attainable level of the markup (the case represented by the rightmost vertical line, $\epsilon>1 /(\theta-1))$, there is too little entry in the steady state with zero inflation. The central bank will generate long-run deflation in order to increase long-run markups and stimulate entry and variety towards their optimal level, trading this off against the welfare costs of non-zero inflation - so equilibrium long-run deflation will actually never be as high as implied by the intersection of LRPC with the vertical line plotting the benefit of variety. 
The optimality of deviations from long-run price stability in our framework relies upon the existence of a non-vertical long-run Phillips curve. While the latter feature is also present in any model of imperfect price adjustment (with no entry) that does not necessarily imply optimal non-zero long-run inflation, it has different welfare consequences in our framework because of the intimate link between entry, variety, and the markup. In Appendix B, we show that our results are actually strengthened under an alternative assumption that weakens the long-run tradeoff between inflation and real activity, namely price indexation.

Proposition 1 pertains to the optimal rate of inflation in the long run (i.e., in steady state). Over the business cycle, the central bank may have an incentive to use inflation deviations from the Ramsey-optimal long-run value under general C.E.S. preferences, since that value does not fully eliminate the inefficiency coming from the failure of (6). The central bank may try to generate inflation that is on average different from the long-run value in order to try to bring markups even closerto the benefit of variety over the cycle. Furthermore, with non-C.E.S. preferences, another distortion may emerge in the flexible-price equilibrium: intertemporal misalignment of markups. This occurs whenever desired, flexible-price markups vary over time. The flexible-price response to shocks is inefficient, and so optimal inflation varies over the business cycle, if the central bank uses it to smooth markup dynamics and undo the implied intertemporal distortion. Note that the distortions implied by misalignment of markup and benefit of variety and time-varying flexibleprice markup coexist under translog preferences: Condition (6) fails, and the desired flexible-price markup varies endogenously over time. We explore below whether this dynamic distortion induces quantitatively significant deviations from price stability.

\section{Optimal Inflation in the Long and in the Short Run: Quantitative Results}

This section quantifies the optimal long-run rate of inflation by means of a numerical example. Moreover, we study the optimal path of inflation and other endogenous variables over the cycle in response to productivity shocks. In the simulations below, we employ the parameter values used in Bilbiie, Ghironi, and Melitz (2007, 2008b). They are set as in Table 4 (and we normalize the steady-state entry cost $f_{E}$ and the steady-state level of productivity $Z$ to 1 ). 
Table 4. Parameters

\begin{tabular}{lllll}
\hline Parameter & $\beta$ & $\delta$ & $\varphi$ & $\kappa$ \\
\hline Value & 0.99 & 0.025 & 0.25 & 77 \\
\hline
\end{tabular}

The choice of the preference parameters, which are specific to the functional form of preferences adopted ( $\theta$ and $\epsilon$ for C.E.S., $\alpha$ for exponential, and $\sigma$ for translog), is discussed in detail in the respective section below. We consider different values for the parameter governing the benefit of variety under general C.E.S. preferences, $\epsilon$, since its value turns out to be crucial for our results. Finally, we will perform robustness checks for different values of the preference parameters, the price stickiness parameter, $\kappa$, and the inverse labor supply elasticity, $\varphi$.

\section{Optimal Long-Run Inflation}

Figure 2 plots the optimal value of the steady-state inflation rate under general C.E.S. as a function of the benefit of variety parameter $\epsilon$, for an interval going from $\epsilon=0$, which implies that there is no independent benefit to the consumer of introducing a new variety to $\epsilon=1$, which is higher than any plausible empirical estimate of long-run average net markups. The elasticity of substitution between goods is set to $\theta=3.8$, a value that is consistent with product-level data (see the discussion in Bilbiie, Ghironi, and Melitz (2007, 2008b)

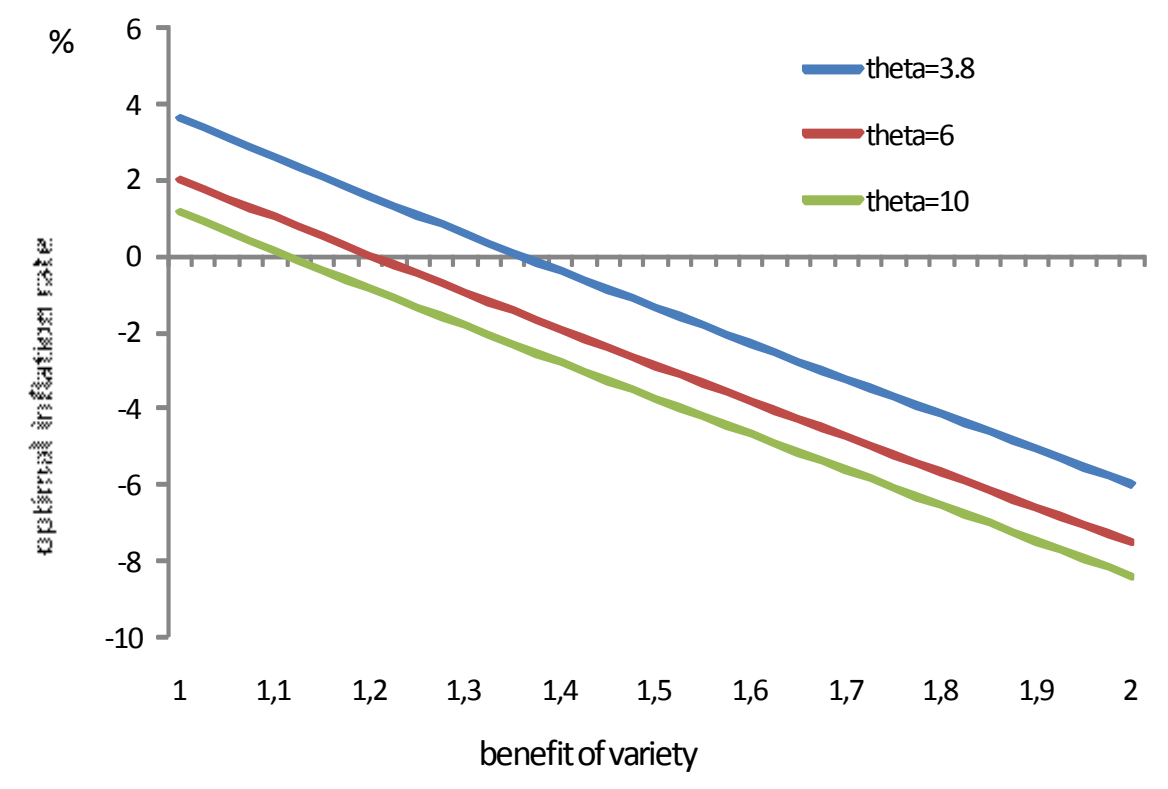


Figure 2: Optimal long-run inflation rate as a function of benefit of variety, benchmark calibration.

Unless the benefit of variety and monopoly power coincide (C.E.S.-D.S. preferences) and the steady state is efficient, the optimal rate of PPI inflation in the Ramsey steady state is non-zero. Specifically, with general C.E.S. preferences, the optimal steady-state inflation rate is positive (negative) when the benefit of variety is smaller (larger) than the markup. Intuitively, when the number of firms is suboptimally larger (smaller) than in the Pareto optimal equilibrium, the Ramsey-optimal steady-state inflation rate becomes positive (negative) to reduce (increase) the markup, so that less (more) firms are attracted to enter the market by less (more) profit opportunities. The central bank chooses a non-zero optimal level of steady-state inflation by trading off the welfare costs of inflation and the benefit of reducing the misalignment of benefit of variety and profit incentive for entry.

As Figure 2 makes clear, the larger the difference between benefit of variety and net markup, the larger the deviation from long-run price stability. Indeed, sizable deviations from price stability occur, ranging from an annual inflation rate of almost 4 percent, when the benefit of variety is nil, to an annual deflation rate of 6 percent, when the benefit of variety is 1 . Higher (lower) values of the elasticity of substitution $\theta$ imply a lower (higher) markup and hence a lower (higher) threshold level of the benefit of variety $\epsilon=1 /(\theta-1)$ at which zero inflation becomes optimal. For example, $\theta=6$ generates a maximum value of long-run optimal inflation of 2 percent (when $\epsilon=0$ ) and a deflation rate of 7 percent when $\epsilon=1$. Different values of the price stickiness parameter $\kappa$ or the inverse labor supply elasticity $\varphi$ do not change the optimal long-run inflation rate significantly (results are available upon request). In Appendix B, we study how our results change under price indexation. We show that a higher degree of price indexation implies even larger optimal deviations from longrun price stability. When indexation is almost full and the long-run Phillips curve is almost vertical, the rate of optimal long-run inflation (or deflation) is very large indeed. For values of the indexation parameter in line with empirical estimates (e.g. Smets and Wouters, 2007), the maximum value of long-run optimal inflation ranges from around 6 percent (when $\epsilon=0$ ) to a deflation rate of 10 percent (when $\epsilon=1$ ).

The quantitative significance of our results on the optimal deviation from long-run price stability hinges upon one's view of a plausible value for the parameter governing the welfare benefit of variety. Unfortunately, to the best of our knowledge, decisive evidence on this parameter is hitherto unavailable. Some estimates exist for the consumer surplus from introducing a new brand of a 
specific product: See e.g. Trajtenberg (1989) for computed tomography (CT) scanners, Hausman (1997, 1999) for Apple-Cinnamon Cheerios and mobile phones, Petrin (2002) for minivans, and Goolsbee and Petrin (2004) for direct broadcast satellites and cable TV.

In our framework, one can find a benchmark, model-implied value of $\epsilon$ by using the following calibration strategy. Specifically, our model implies the following relationship between PPI inflation, CPI inflation, and the benefit of variety expressed as the relative price of each symmetric variety:

$$
\frac{1+\pi_{t}}{1+\pi_{t}^{C}}=\frac{\rho_{t}}{\rho_{t-1}}=\frac{\rho\left(N_{t}\right)}{\rho\left(N_{t-1}\right)}
$$

where the second equality follows from the fact that, in general, the benefit of variety (relative price) is a function of the number of varieties available. Taking logs under the general C.E.S. preference specification, $\rho\left(N_{t}\right)=\left(N_{t}\right)^{\epsilon}$ (of which C.E.S.-D.S. is a special case), and allowing for long-run growth in the number of varieties yields:

$$
\epsilon=\frac{\pi-\pi^{C}}{g_{N}},
$$

where we used $\pi \simeq \ln (1+\pi)$ and $g_{N}$ is the average net growth rate in the number of varieties. For reasons discussed above (Boskin et al, 1996, Broda and Weinstein, 2010), the CPI is subject to an upward bias, a large part of which comes precisely from not accounting for new varieties: $\hat{\pi}^{C}=\pi^{C}+$ bias, where $\hat{\pi}^{C}$ is data, measured CPI inflation. Therefore, we need to account for this bias when constructing our calibrated $\epsilon$ by using measured CPI inflation $\hat{\pi}^{C}$. The magnitude of the bias (the portion due to not accounting for new goods) is 0.6 percentage points per year in the Boskin report and 0.8 percentage points in Broda and Weinstein (2010). The differential in the data between (post-1982) average annual PPI and CPI inflation rates $\pi-\hat{\pi}^{C}$ is at least -0.5 percentage points (and at most -0.8) across a wide range of indexes. Finally, the average growth rate of varieties since 1980 calculated by Bils and Klenow (2001) is around 2 percent. This calculation therefore suggests that the benefit of variety parameter $\epsilon$ lies between 0.05 and 0.15 , and it is in any case not very far from zero-implying that the optimal long-run rate of inflation is positive. However, a direct aggregate measure of the welfare benefit of new products is not available, and some argue that it is "probably not feasible" (Bils and Klenow, 2001). Therefore, our exercise should be viewed as on the one hand providing a novel argument for potentially significant deviations from long-run price stability, and on the other pointing to the need for more empirical investigation into the nature of preferences for variety, since this - along with markups - is the single most important 
determinant of optimal deviations from price stability in a framework with endogenous product variety.

This new role of the steady-state inflation rate is absent in the standard New Keynesian model with fixed variety. It is akin to the role of a positive capital income tax in a variety of scenarios, once we note that inflation in this model has the same flavor as a tax on profits and thus an indirect tax on dividend income (see Bilbiie, Ghironi, and Melitz, 2008b). Most specifically, Bilbiie, Ghironi, and Melitz (2008a) have shown, in a version of our model with flexible prices, that a (Pigouvian) tax on dividend income financed by lump-sum taxes can entirely eliminate the steady-state distortion coming from the mismatch of market incentives and consumer surplus of a new variety. Chugh and Ghironi (2009) show that this finding extends to a (Ramsey) setting in which lump-sum taxes are unavailable. $^{20}$

\section{Optimal Inflation over the Business Cycle}

What is the optimal path of inflation over the business cycle in response to productivity shocks? To answer this question, we log-linearize the three constraints in Table 3 and the four first-order conditions in Appendix A around the steady state with optimal long-run inflation, and we study the responses to shocks under C.E.S., exponential, and translog preferences. All responses are expressed in percentage deviations from steady state of the respective variable, with the important exception of inflation and nominal interest rates, which are expressed in basis point deviations from steady state.

\section{C.E.S. Preferences}

Figure 3 shows the impulse responses of key endogenous variables (number of firms, inflation rate, consumption, hours, nominal and real interest rates, price level, and inflation) to a one-percent positive productivity shock with autoregressive persistence 0.95 under C.E.S.-D.S. preferences. These dynamics are compared to the benchmark responses under flexible prices, which are essentially the same as in Bilbiie, Ghironi, and Melitz (2007).

\footnotetext{
${ }^{20}$ In models with physical capital, incomplete asset markets are a standard justification for the optimality of a positive long-run tax on capital income. As shown by Aiyagari (1995), agents over-save in a Bewley (1977) economy with uninsured idiosyncratic shocks, for self-insurance reasons. A positive capital income tax rate can be welfareenhancing by reducing a suboptimally high capital level. Insofar as they pertain to the inability of the market economy to internalize an externality and align incentives and benefits between groups of agents in the economy, our results are also related to those in Ljungqvist and Uhlig (2000) and Choudhary and Levine (2006), who study tax policies designed to internalize the externalities from external habits.
} 

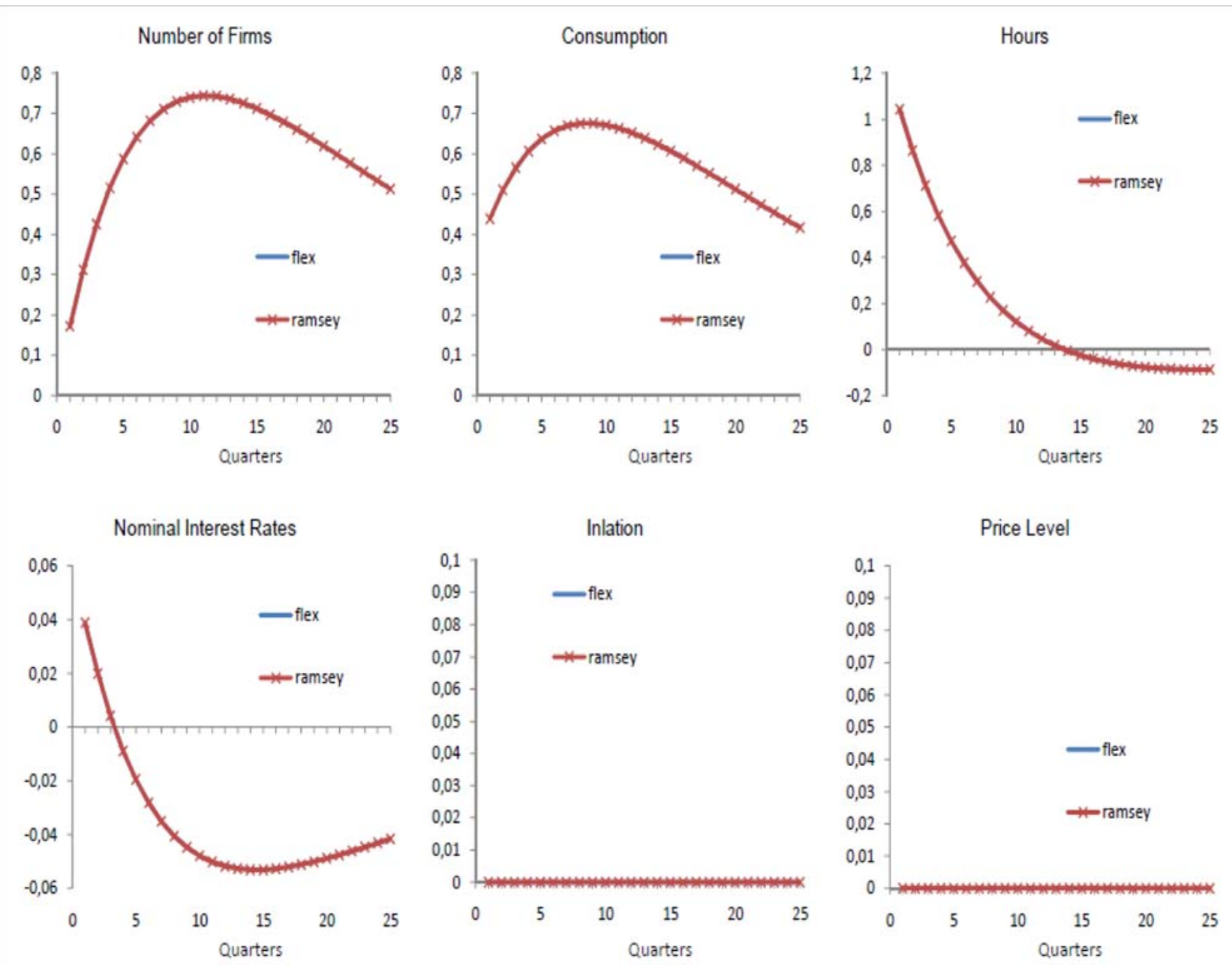

Figure 3: Impulse responses to a productivity shock for C.E.S.-D.S. preferences under Ramsey policy (red, crossed line) and flexible prices (blue line). Inflation and interest rate are in basis points deviations, the rest in percentage deviations from steady state.

As Figure 3 shows, optimal policy under C.E.S.-D.S. preferences consists of replicating the flexible-price solution. Although fluctuations in the flexible-price equilibrium are not optimal (because of the presence of a steady-state distortion generated by monopolistic competition in the goods market combined with elastic labor supply), the central bank does not try to smooth these fluctuations using inflation. Optimal policy consists therefore of keeping the producer price level constant. Nominal interest rates move (in line with the underlying determinants of the real interest rate) in order to bring about this outcome. In this sense, policy needs to be activist as in Khan, King, and Wolman (2003). This conclusion echoes the result obtained in fixed-variety models when there are no money demand distortions (see e.g. Khan, King, and Wolman, 2003) and is robust 
to changes in labor supply elasticity and the elasticity of substitution between goods (result are available upon request). To sum up, under C.E.S.-D.S. preferences, our conclusion is that the literature's finding that price stability is optimal both in the long run and over the (productivity shocks-driven) business cycle is robust to the introduction of endogenous entry and variety.

Next, we ask whether this conclusion changes when the benefit of variety and the net markup no longer coincide. Figures 4 and 5 plot the impulse responses for the same set of variables under general C.E.S. preferences for $\epsilon=0.1$ and $\epsilon=1$, respectively, and compare them with the flexibleprice responses.

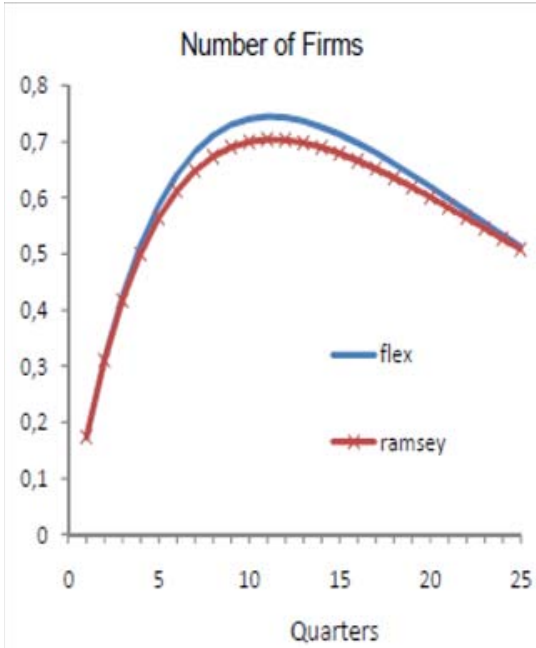

Nominal Interest Rates

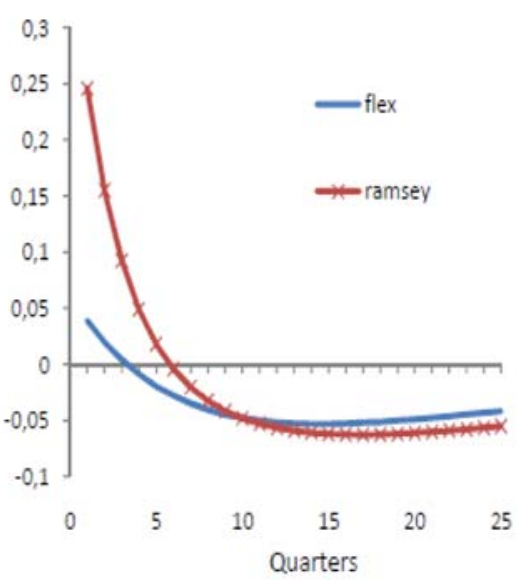

Consumption

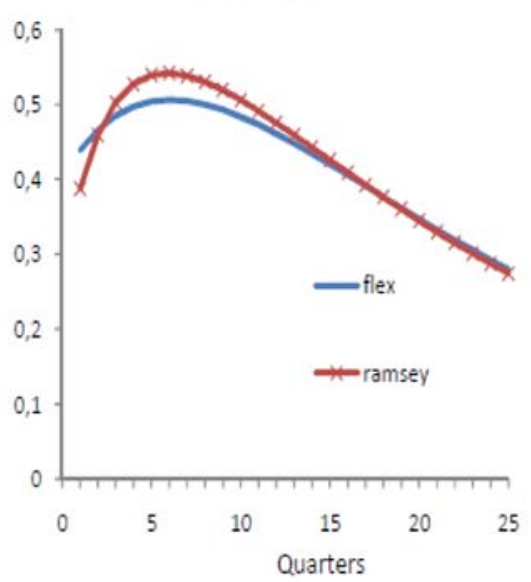

Inlation

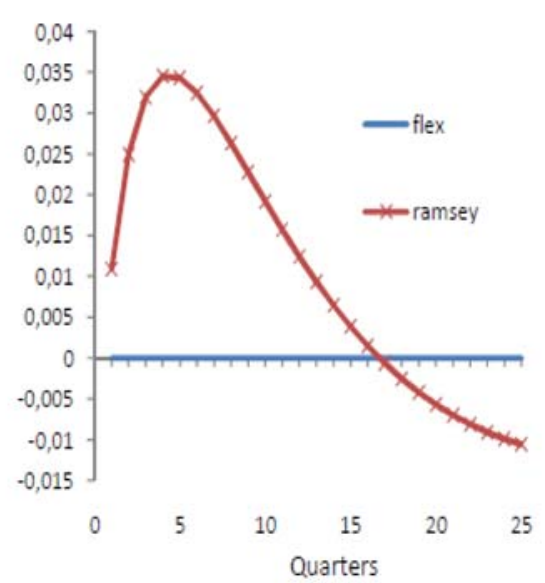

Hours

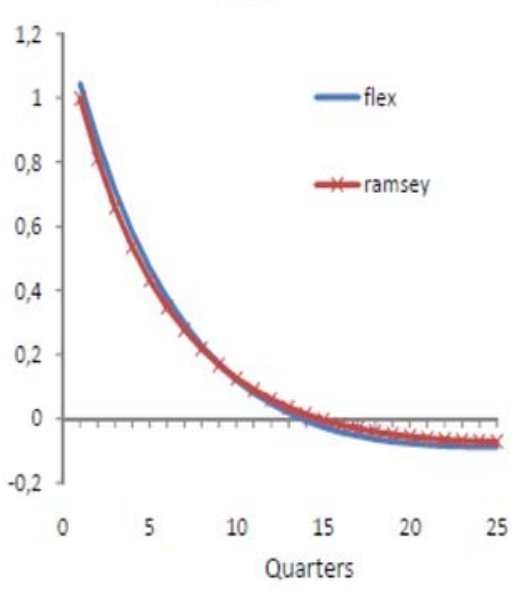

Price Level

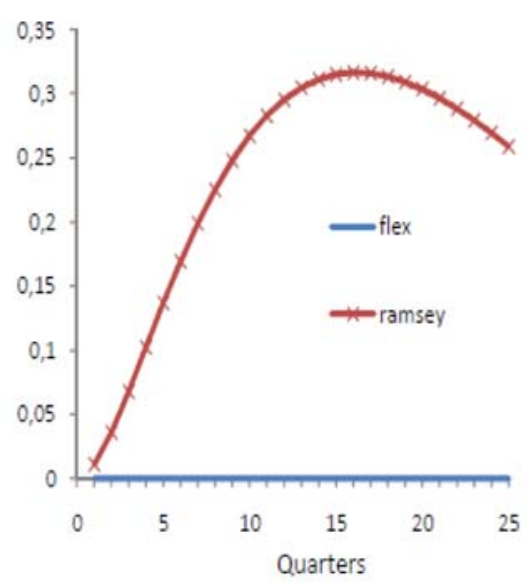

Figure 4: Impulse responses to a productivity shock for general C.E.S. preferences with $\epsilon=0.1$ under Ramsey policy (red, crossed line) and flexible prices (blue line). Inflation and interest rate are in basis points deviations, the rest in percentage deviations from steady state. 

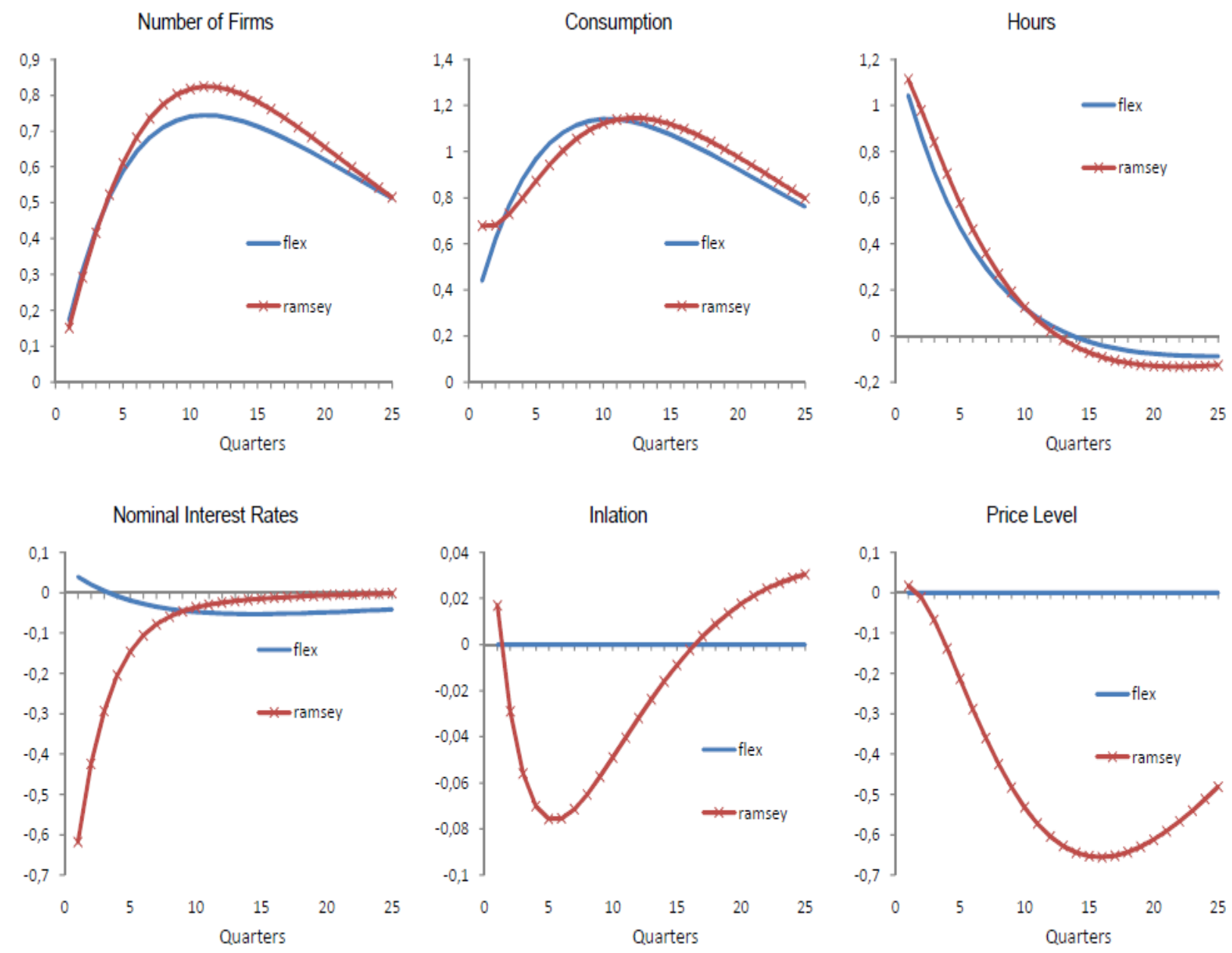

Figure 5: Impulse responses to a productivity shock for general C.E.S. preferences with $\epsilon=1$ under Ramsey policy (red, crossed line) and flexible prices (blue line). Inflation and interest rate are in basis points deviations, the rest in percentage deviations from steady state.

In both cases, there are optimal deviations of inflation rate over the cycle (relative to its longrun, steady-state value), which translate into differences in real variables. The reason is that the optimal long-run policy does not entirely eliminate the steady-state distortion from the misalignment between the consumer benefit of a new variety and the firms' incentives to introduce that variety. When the benefit of variety is lower (higher) than the steady-state markup, the central bank engineers an inflationary (deflationary) path, relative to the long-run trend, in order to try to bring average markups (by reducing and increasing them, respectively) even closer to the benefit of variety. The result is less (more) entry - and hence a lower (higher) number of firms - under the 
optimal policy than in the flexible-price equilibrium. The paths of consumption and hours are also different from the flexible-price solutions, although not significantly so. Quantitatively, however, the movements in inflation are minuscule: The maximum inflation rate in the first scenario $(\epsilon=0.1)$ is a mere 0.05 basis points deviation from steady state, whereas in the second scenario $(\epsilon=1)$, the maximum deflation rate is a 0.1 basis points deviation from steady state; these translate into small deviations of the price level (maximum values of 0.4 percent and -1 percent, respectively). Therefore, we conclude that the monetary authority does not make use of the leverage it has to influence real activity in the short run, despite facing a distorted steady state ${ }^{21}$; Quantitatively, the welfare benefits of further closing the inefficiency wedge are outweighed by the welfare costs of inflation. This result is consistent with the findings of Khan, King, and Wolman (2003) that Ramsey-optimal responses to productivity shocks are close to the flexible-price ones in the presence of a different type of distortions (monetary inefficiency and time costs); a similar result occurs in Woodford (2003) and Benigno and Woodford (2005), when steady-state government spending is zero. More generally, the result that optimal inflation does not vary significantly over the business cycle is consistent with a standard tax smoothing motive (see Golosov and Tsyvinski, 2006, for a review): The policymaker tries to smooth distortions over time, and this is achieved in our framework by minimizing inflation variability. ${ }^{22}$

\section{Exponential Preferences}

The role of optimal policy in alleviating the dynamic entry distortion (Distortion 3) is best illustrated by using exponential preferences. Recall that for this class of preferences, desired markups vary with the number of producers (because the elasticity of substitution between goods changes), but the benefit of a new variety and the net desired markup are equal (the static entry distortion does not operate). Therefore, the conditions of Proposition 1 are met and zero long-run inflation is optimal. To understand the inflation dynamics implied by these preferences, we abstract for the moment from the welfare cost of inflation and note that loglinearizing the New Keynesian Phillips

\footnotetext{
${ }^{21}$ Appendix B shows that the short-run conclusions are not significantly affected by price indexation.

${ }^{22}$ Inflation in our model resembles an indirect tax on dividends (see Bilbiie, Ghironi, and Melitz, 2008b); In a model similar to ours but with flexible prices and focusing on fiscal policy, Chugh and Ghironi (2009) show that smoothing inefficiency wedges can be achieved by smoothing dividend income taxes over the cycle.
} 
curve (3) around the (optimal, under these preferences) zero-inflation steady-state we obtain:

$$
\begin{aligned}
\pi_{t} & =\beta(1-\delta) E_{t} \pi_{t+1}-\frac{\theta(N)-1}{\kappa}\left(\mu_{t}-\mu_{t}^{*}\right), \\
\text { where } \mu_{t}^{*} & =-\frac{\theta^{\prime}(N) N}{\theta(N)(\theta(N)-1)} \mathrm{N}_{t}=-\frac{1}{1+\alpha N} \mathrm{~N}_{t}
\end{aligned}
$$

is the desired, flexible-price markup (we have used $\theta^{\prime}(N)=\alpha$ ). Note that variations in desired markups are akin to the "cost-push shocks" used in the New Keynesian literature to justify shortrun deviations from price stability (see e.g. Woodford, 2003); different from those shocks, however, variations in desired markups are entirely endogenous here.

A central bank who wanted to entirely undo the dynamic entry distortion would set inflation to aim for a constant path of realized markups, $\mu_{t}=0$; if this policy were feasible, it would imply that inflation obeys (setting $\mu_{t}=0$ in (8) and iterating forward):

$$
\pi_{t}=\frac{\theta(N)-1}{\kappa} E_{t} \sum_{i=0}^{\infty}(\beta(1-\delta))^{i} \mu_{t+i}^{*}
$$

Intuitively, the central bank needs to neutralize movements in the "natural", flexible-price markup generated by entry. Since a positive productivity shock generates an increase in entry and the number of producers and hence a fall in desired markups (by (9)), the central bank will typically need to engineer a deflationary path, in order to keep realized markups constant. However, using inflation entails resource costs, which need to be weighed against these benefits - and so inflation variations under optimal policy will typically be smaller than those implied by (10). 

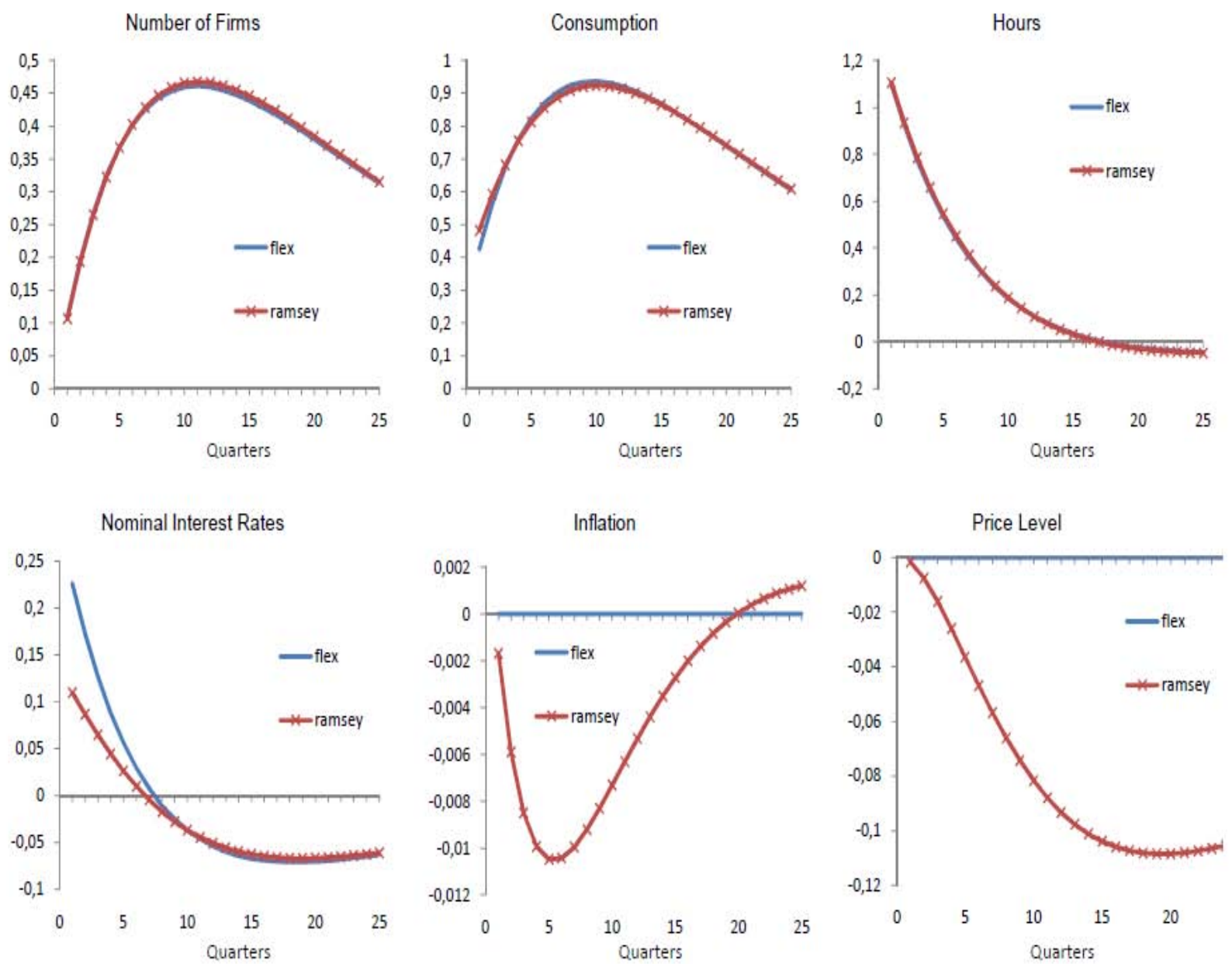

Figure 6: Impulse responses to a productivity shock for exponential preferences with $\alpha=0.1$ under Ramsey policy (red, crossed line) and flexible prices (blue line). Inflation and interest rate are in basis points deviations, the rest in percentage deviations from steady state.

Figure 6 plots the responses of the set of macroeconomic variables of interest for our baseline set of parameter values. We use a low value of $\alpha=0.1$, which implies a high elasticity of the desired markup to the number of firms (see (9)) and hence relatively high variation of optimal inflation, to give the model the best chance to generate deviations from short-run price stability. However, Figure 6 shows that even under this extreme parameterization, deviations from price stability are minimal: the maximum deflation rate (achieved after five quarters) is a mere 0.01 basis points, translating into a maximum fall in the price level of around 0.1 percent after 20 quarters. We conclude that the dynamic entry distortion from time-varying desired markups in itself does not justify deviations from price stability, even when using a calibration that implies a very large distortion. 


\section{Translog Preferences}

Long-run zero inflation is never optimal under translog preferences, because the benefit of variety is always half the size of the steady-state desired markup. Therefore, optimal policy will always use a positive inflation rate, seeking to align net markup and benefit of variety (recall Figure 2 and the corresponding discussion). For instance, under the baseline calibration used by Bilbiie, Ghironi, and Melitz (2008b), $(\sigma=0.353$, which implies that the elasticity of substitution between goods, $1+\sigma N^{\text {translog}}$, is the same as that used under C.E.S., i.e., 3.8), the benefit of variety is 0.178 and the annualized inflation rate is 1.03 percent. The question we ask here is whether, over the cycle, the central bank has incentives to use inflation rates that are quantitatively different from their long-run optimal value. There are in principle two reasons why the answer could be positive. The first one is that the steady-state wedge due to the misalignment of benefit of variety and markup is not fully closed by the choice of the optimal long-run inflation rate: therefore, the central bank may use positive short-run inflation to bring markups even closer to the benefit of variety - very much like under C.E.S. preferences when $\epsilon<\mu-1$. The second reason why the central bank may use inflation over the cycle is that the flexible-price equilibrium is inefficient not only in levels, but also over time, because the flexible-price markup is endogenously time-varying (just as under the exponential preferences covered above). By the same mechanism as for exponential preferences, optimal policy implies short-run deflation in order to smooth the path of markups and hence minimize the dynamic entry distortion.

The net effect on short-run inflation of these two forces (alleviating the static and dynamic entry distortions) results in short-run deflation for standard calibrations. Figure 7 plots impulse responses of macroeconomic variables under the Ramsey-optimal policy for a rather extreme parameterization of $\sigma=0.1$, implying a high elasticity of desired markups to number of producers, and hence a strong dynamic entry distortion - therefore, these results can be viewed as an upper bound on the degree of deviations from short-run price stability. As before, we also plot the benchmark responses obtained in the flexible-price equilibrium in order to gauge the quantitative significance of deviations from short-run price stability under optimal policy. As the figure shows, the deviations from steady-state inflation implied by optimal policy are again insignificant. The maximum value of the deflation rate is a mere 0.015 basis points, translating into a 0.22 percent fall in the price level over 25 quarters. The responses of consumption, number of firms, and hours worked are almost identical to their flexible-price counterparts. Therefore, we conclude that short-run price stability (around a non- 
zero long-run trend) is close to optimal when distortions in the form of both inefficient fluctuations in flexible-price markups and misalignement of markup and benefit of variety are present. This result is robust to considering different elasticities of the desired markup to the number of firms (a lower elasticity implies that the dynamic distortion is smaller and therefore reduces even further the scope for inflation variations) and different values for the other parameters; the results of these robustness exercises are available upon request.
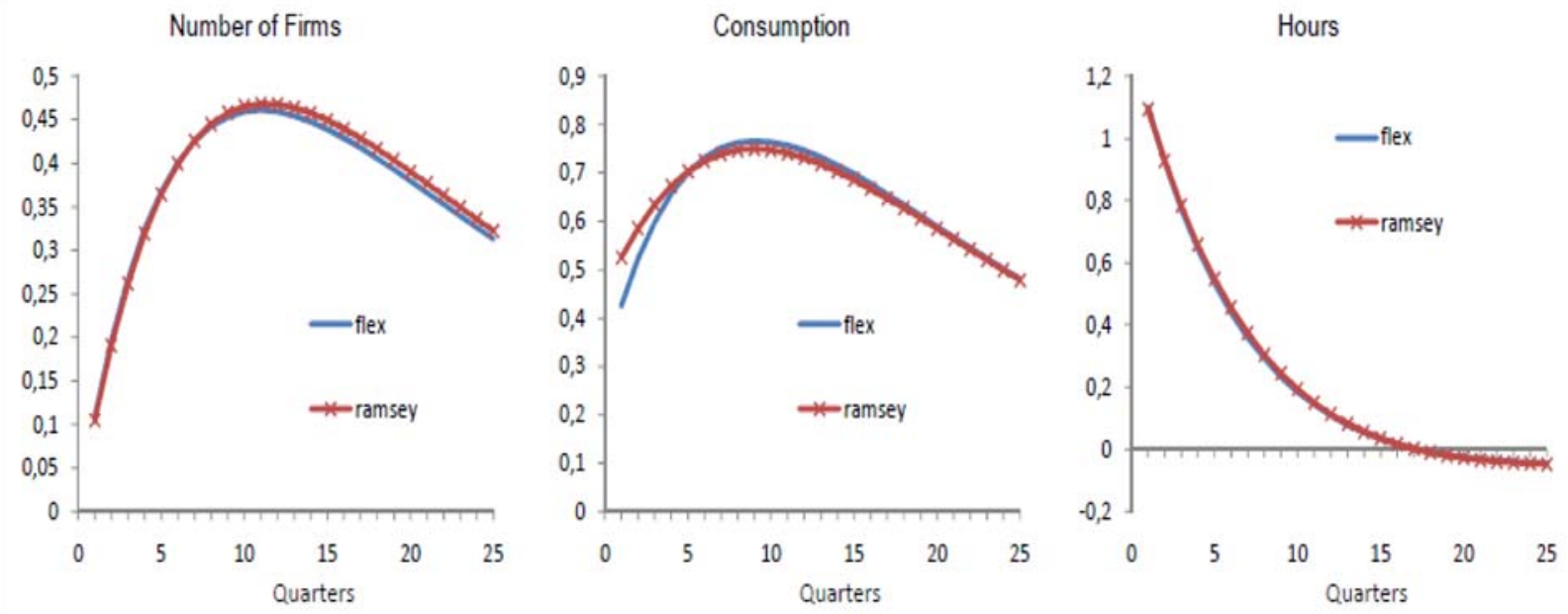

Nominal Interest Rates
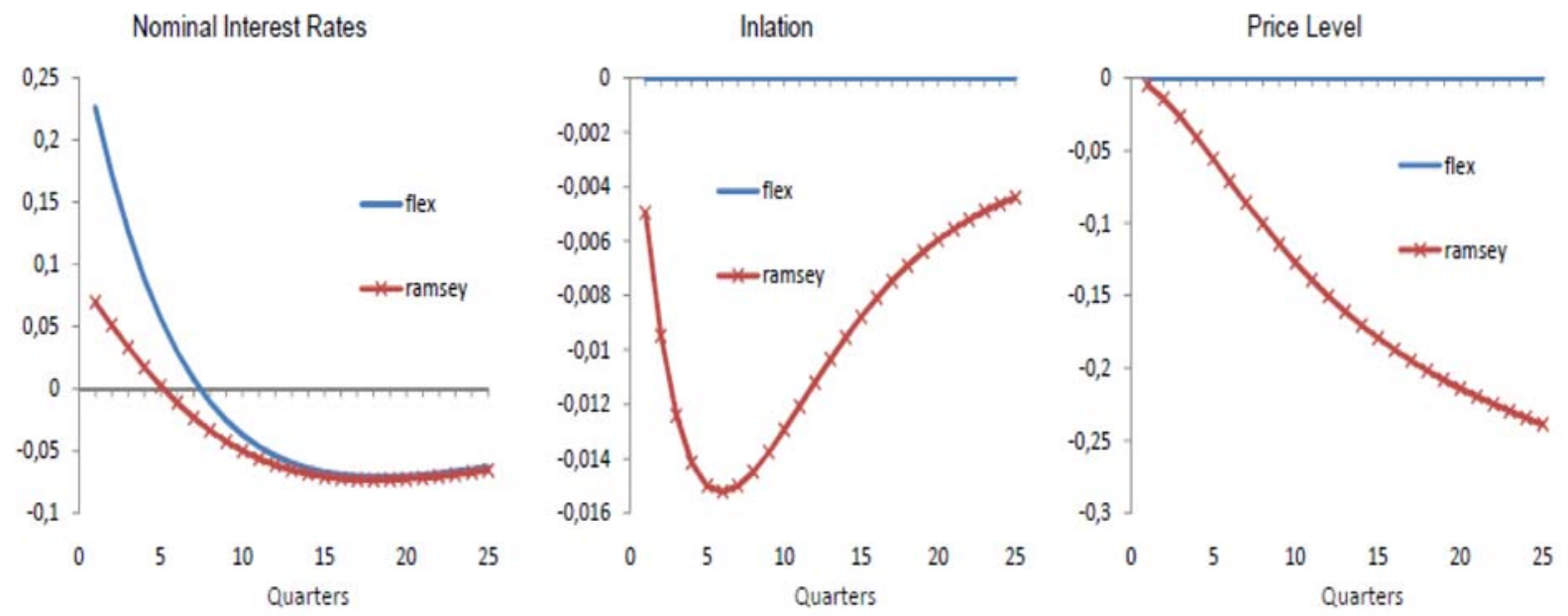

Figure 7: Impulse responses to a productivity shock for translog preferences with $\sigma=0.1$ under Ramsey policy (red, crossed line) and flexible prices (blue line). Inflation and interest rate are in basis points deviations, the rest in percentage deviations from steady state. 


\section{The Welfare Cost of Price Stability}

The analysis above suggests that undoing the sticky-price distortion is suboptimal in the long-run equilibrium of an economy with product creation driven by a preference for variety and monopoly profits when the benefit of variety to consumers is not aligned with the market incentive for entry (the net markup). However, price stability (around a non-zero trend) is close to optimal in the short run. Our final exercise assesses quantitatively the welfare cost of price stability. To that end, we compute two welfare losses: a static and a dynamic one. ${ }^{23}$ The static welfare loss is defined as the difference between lifetime welfare under a policy that fully stabilizes PPI inflation around its Ramsey-optimal value and the "alternative" policy whereby the monetary authority stabilizes PPI inflation at zero in the short and the long run; The purpose of this exercise is to isolate the role of what we earlier called the static entry distortion. The dynamic welfare loss is defined as the difference between lifetime welfare under Ramsey-optimal policy and the "alternative" policy whereby the monetary authority stabilizes PPI inflation around its Ramsey-optimal long-run value; this exercise isolates the role of the dynamic entry distortion. All computations assume that productivity shocks have a persistence of 0.95 and a standard deviation of 0.007 , values that are standard in the business cycle literature (details of our computations are available upon request).

\footnotetext{
${ }^{23}$ Both losses are defined, in the Lucas (1987) tradition, as the units of steady-state consumption that we would need to give the household in order to make it indifferent (in terms of expected present discounted utility) between a certain policy and a benchmark equilibrium (which may be the Ramsey-optimal equilibrium); see also Schmitt-Grohé and Uribe (2007) for similar welfare calculations in a different model.
} 


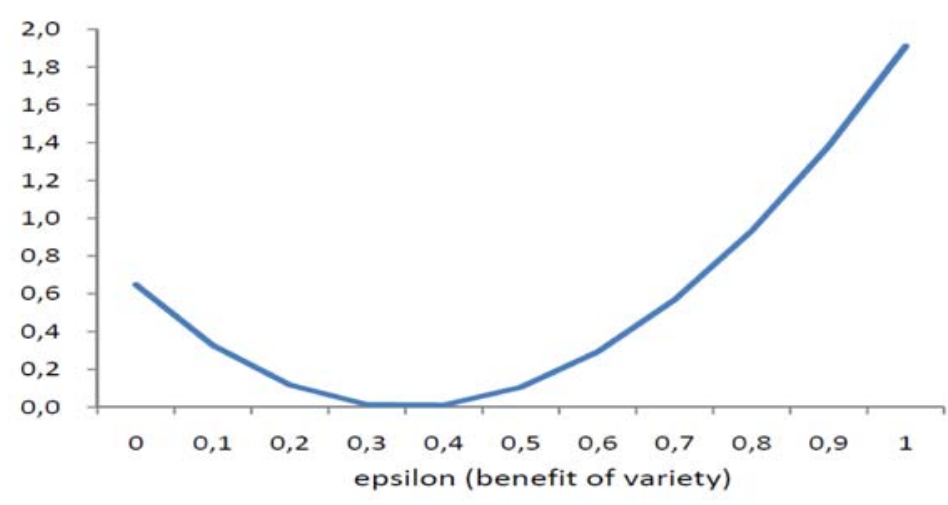

Dynamic welfare loss

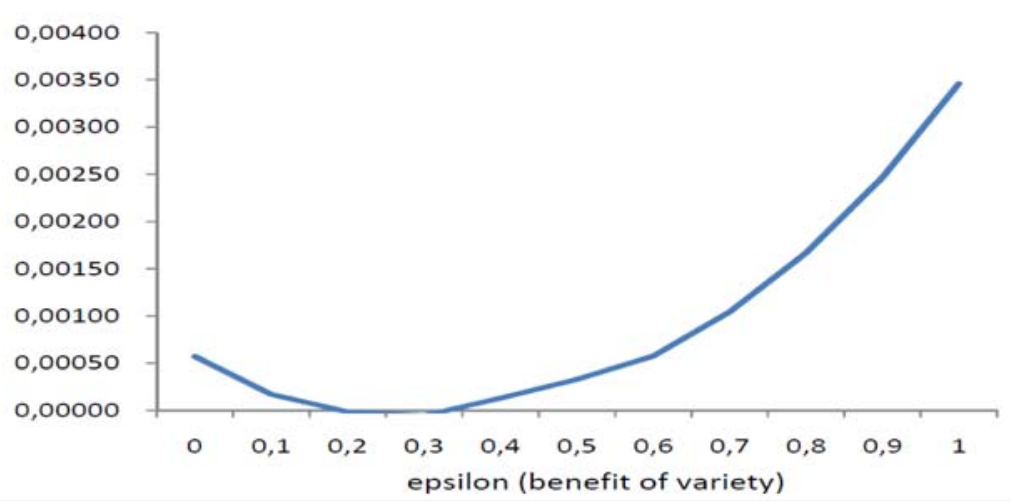

Figure 8: Static and dynamic welfare losses in percentage points of steady-state consumption, general C.E.S. preferences.

Figure 8 plots the static and dynamic welfare losses for general C.E.S. preferences, as a function of the benefit of variety parameter. The upper panel shows that the welfare cost of pursuing longrun price stability can be very high, depending on the benefit of variety. The loss is U-shaped and attains a minimum value of zero when preferences are of the C.E.S.-D.S. form, consistent with our result that price stability is optimal in that case. Otherwise, the loss ranges from 0.64 percent of steady-state consumption (when the benefit of variety is negligible) to almost 2 percent when the benefit of variety is $\epsilon=1$. Importantly, however, the dynamic welfare loss (plotted in the lower panel) shows that once the central bank stabilizes prices at the Ramsey-optimal target in all periods, the loss is virtually zero: Its maximum value is merely 0.003 percent of steady-state consumption for the maximum value of $\epsilon$ that we consider. 


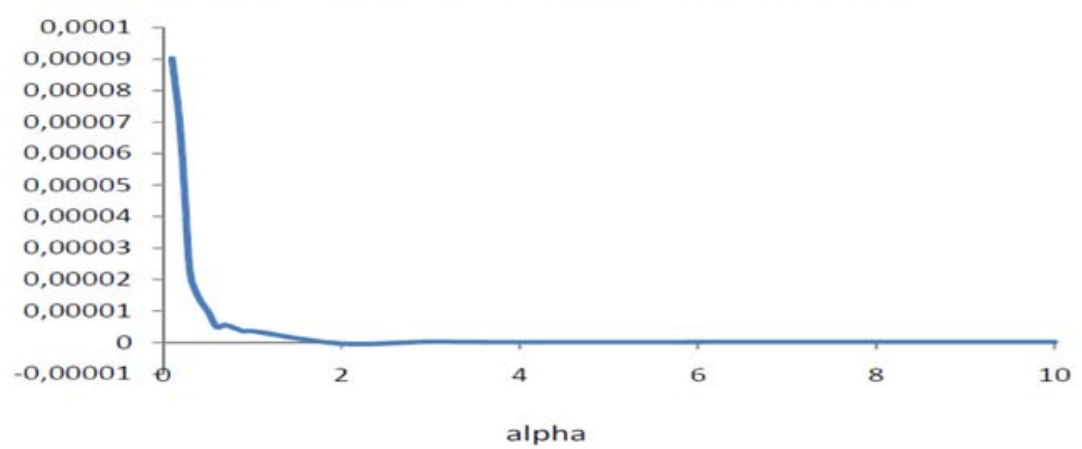

Static welfare loss, Translog preferences

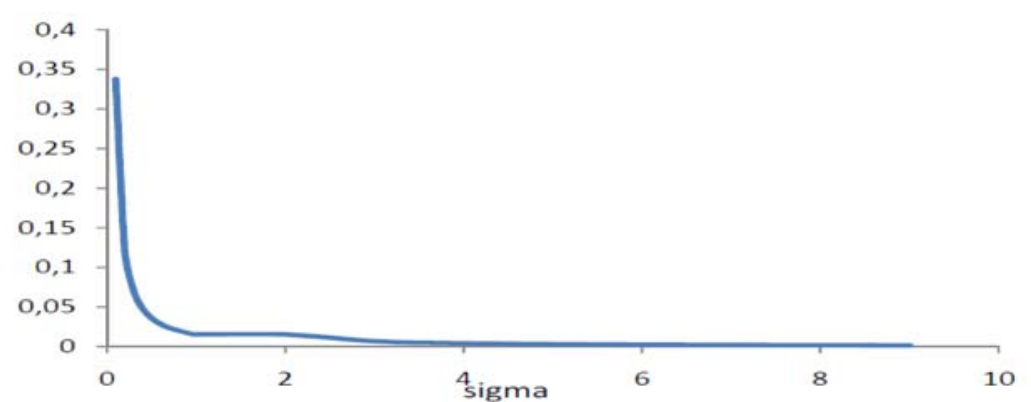

Dynamic welfare loss, Translog preferences

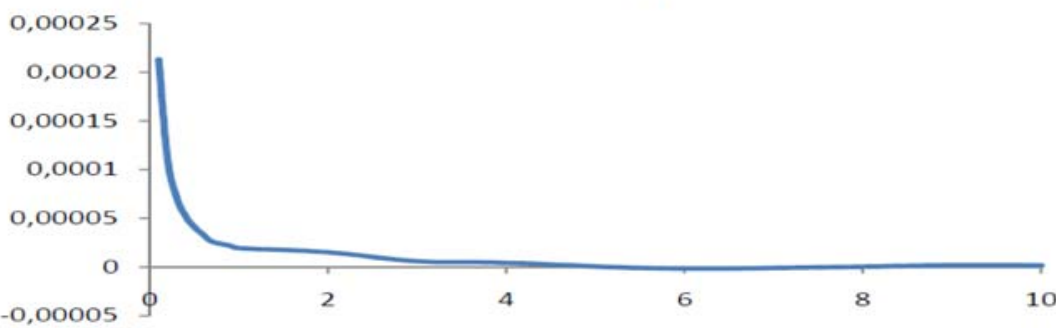

sigma

Figure 9: Dynamic welfare loss for exponential preferences, and static and dynamic welfare losses for translog preferences, all in percentage points of steady-state consumption.

Figure 9 plots the dynamic welfare loss for exponential preferences, and the static and dynamic welfare losses under translog (the static loss under exponential - not plotted - is zero because the static entry distortion does not operate). For exponential preferences, the dynamic loss plotted in the top panel is negligible: Even for values of $\alpha$ close to zero (implying that the dynamic entry distortion is "large") the loss from fully stabilizing prices around the Ramsey-optimal long-run trend is almost zero (0.00009 percentage points at most). The middle panel plots the static loss under translog, as a function of $\sigma$. The loss is sizable (around 0.3 percent) for very low values of 
$\sigma$ because in that case the static entry distortion is high (recall that the static entry distortion under translog is measured by half the markup - the difference between net markup and benefit of variety - and the markup is a decreasing function of $\sigma$, for given $N$ ). The lower panel shows that the dynamic entry distortion is nevertheless negligible: Even at values of $\sigma$ close to zero, implying a very large distortion, the dynamic loss merely attains 0.0002 percentage points.

Our results, pointing to negligible dynamic welfare losses for all types of preferences considered, reinforce our previous finding that dynamic responses to productivity shocks are very close under Ramsey-optimal policy and flexible prices. We conclude that the loss from fully stabilizing PPI inflation is negligible once the long-run inflation target has been optimally chosen taking into account the nature of preferences and market incentives for entry.

\section{Conclusions}

A large literature studies optimal monetary policy in the presence of imperfect price adjustment and other real or monetary distortions. A general conclusion of this literature is that the optimal long-run rate of inflation is zero or very close to zero. Moreover, in an environment in which productivity shocks are the only source of uncertainty, perfectly stabilizing prices over the business cycle (and hence replicating the flexible-price allocation) is optimal, or nearly so. This paper argues that the optimal long-run rate of inflation can be significantly different from zero in an environment with endogenous entry and product variety, but price stability (around this long-run trend) is close to optimal over the cycle. The sign and magnitude of the optimal long-run inflation rate depend on the balance between the market incentives for entry (measured by the steady-state markup) and the welfare benefit of product variety to consumers. When the market outcome results in too much entry relative to what the consumer values (when the markup is higher than the benefit of variety), positive long-run inflation is optimal because it erodes long-run markups and profit margins, and it reduces entry. In the opposite case, long-run deflation is optimal, because it increases steady-state markups and hence provides more incentives for entry. The long-run rate of inflation is zero only in the knife-edge case of C.E.S.-D.S. preferences, for which the net markup is equal to the benefit of variety. Finally, the welfare loss resulting from not recognizing the non-zero long-run target for inflation can be sizable, depending on the benefit of variety parameter; In contrast, the welfare loss due to stabilizing prices in the short run is negligible, once the long-run inflation target has been chosen optimally.

Our analysis provides a hitherto unexplored argument for potentially significant deviations from 
long-run price stability, with deviations of potential magnitudes not encountered in other economic environments no matter the type of underlying distortions (see Schmitt-Grohé and Uribe, 2011, for an exhaustive review of the robustness of the "zero optimal inflation" policy prescription). Since the single most important determinant of optimal long-run inflation is the balance of markups and benefit of variety, our findings point to the need for continued study of the determinants of markups and serious empirical investigation of the nature of preferences for variety.

\section{References}

[1] Adão, Bernardino, Isabel Correia, and Pedro Teles (2003). "Gaps and Triangles." Review of Economic Studies, 70(4), 699-713.

[2] Aiyagari, S. Rao (1995). "Optimal Capital Income Taxation with Incomplete Markets, Borrowing Constraints, and Constant Discounting." Journal of Political Economy, 103(6), 1158-1175.

[3] Arseneau, David M., and Sanjay K. Chugh (2008). "Optimal Fiscal and Monetary Policy with Costly Wage Bargaining." Journal of Monetary Economics, 55(8), 1401-1414.

[4] Benassy, Jean-Pascal (1996). "Taste for Variety and Optimum Production Patterns in Monopolistic Competition." Economics Letters, 52(1), 41-47.

[5] Benigno, Pierpaolo, and Michael Woodford (2005). "Inflation Stabilization and Welfare: The Case of a Distorted Steady State." Journal of the European Economic Association, 3(6), 11851236.

[6] Bergin, Paul R., and Giancarlo Corsetti (2008). "The Extensive Margin and Monetary Policy." Journal of Monetary Economics, 55(7), 1222-1237.

[7] Bewley, Truman (1977). "The Permanent Income Hypothesis: A Theoretical Formulation." Journal of Economic Theory, 16(2), 252-292.

[8] Bilbiie, Florin O., Fabio Ghironi, and Marc J. Melitz (2007). "Endogenous Entry, Product Variety and Business Cycles." NBER Working Paper 13199.

[9] Bilbiie, Florin O., Fabio Ghironi, and Marc J. Melitz (2008a). "Monopoly Power and Endogenous Product Variety: Distortions and Remedies." NBER Working Paper 14383. 
[10] Bilbiie, Florin O., Fabio Ghironi, and Marc J. Melitz (2008b). "Monetary Policy and Business Cycles with Endogenous Entry and Product Variety." In Acemoglu, Daron, Kenneth S. Rogoff, and Michael Woodford, eds., NBER Macroeconomics Annual 200\%, University of Chicago Press, Chicago, IL, pp. 299-353.

[11] Billi, Roberto M. (2011). "Optimal Inflation for the U.S. Economy." Forthcoming in the American Economic Journal: Macroeconomics.

[12] Bils, Mark, and Pete Klenow (2001) "The Acceleration in Variety Growth." American Economic Review Papers and Proceedings, 91, 274-280.

[13] Boskin, Michael J., Ellen R. Dulberger, Robert J. Gordon, Zvi Griliches, and Dale Jorgenson (1996). "Toward a More Accurate Measure of the Cost of Living." Final Report to the Senate Finance Committee, December 4.

[14] Broda, Christian, and David E. Weinstein (2010). "Product Creation and Destruction: Evidence and Price Implications." American Economic Review, 100(3), 691-723.

[15] Calvo, Guillermo A. (1983). "Staggered Prices in A Utility-Maximizing Framework." Journal of Monetary Economics, 12(3), 383-398.

[16] Chari, Varadarajan V., Lawrence J. Christiano, and Patrick J. Kehoe. (1991) "Optimal Fiscal and Monetary Policy: Some Recent Results." Journal of Money, Credit and Banking, 23(3), 519-539.

[17] Choudhary, M. Ali, and Paul Levine (2006). "Idle Worship." Economics Letters, 90(1), 77-83.

[18] Chugh, Sanjay K. (2006). "Optimal Fiscal and Monetary Policy with Sticky Wages and Sticky Prices." Review of Economic Dynamics 9(4), 683-714.

[19] Chugh, Sanjay K., and Fabio Ghironi (2009). "Optimal Fiscal Policy with Endogenous Product Variety." Mimeo, University of Maryland and Boston College.

[20] Correia, Isabel, Juan Pablo Nicolini, and Pedro Teles (2008). "Optimal Fiscal and Monetary Policy: Equivalence Results," Journal of Political Economy, 116(1), 141-170.

[21] Dixit, Avinash K., and Joseph E. Stiglitz (1977). "Monopolistic Competition and Optimum Product Diversity." American Economic Review, 67(3), 297-308. 
[22] Erceg, Christopher J., Dale W. Henderson, and Andrew T. Levin (2000). "Optimal Monetary Policy with Staggered Wage and Price Contracts." Journal of Monetary Economics, 46(2), 281-313.

[23] Faia, Ester (2009). "Ramsey Monetary Policy with Labor Market Frictions." Journal of Monetary Economics, 56(4), 570-581.

[24] Faia, Ester (2010). "Oligopolistic Competition and Optimal Monetary Policy." Mimeo, Goethe University Frankfurt.

[25] Feenstra, Robert C. (2003). "A Homothetic Utility Function for Monopolistic Competition Models, without Constant Price Elasticity." Economics Letters, 78(1), 79-86.

[26] Golosov, Mikhail and Aleh Tsyvinski (2006) "Optimal Fiscal and Monetary Policy with Commitment", forthcoming in The New Palgrave: A Dictionary of Economics, 2nd edition, Palgrave Macmillan.

[27] Goolsbee, Austan, and Amil Petrin (2004). "The Consumer Gains from Direct Broadcast Satellites and the Competition with Cable TV," Econometrica, 72(2), 351-381.

[28] Gordon, Robert J. (2000). "The Boskin Commission Report and its Aftermath." in Silver, Mick, and David Fenwick, eds., Proceedings of the Measurement of Inflation Conference, University of Chicago Press, Chicago, IL, pp. 258-282.

[29] Gordon, Robert J. (2006). "The Boskin Commission Report: A Retrospective One Decade Later." International Productivity Monitor, Spring, 7-22.

[30] Hausman, Jerry A. (1997). "Valuation of New Goods Under Perfect and Imperfect Competition." in Bresnahan, Timothy, and Robert J. Gordon, eds., The Economics of New Goods, University of Chicago Press, Chicago, IL, pp. 209-237.

[31] Hausman, Jerry A. (1999) "Cellular Telephones, New Products, and the CPI." Journal of Business and Economic Statistics, 17(2), 188-194.

[32] Ireland, Peter (1996). "The Role of Countercyclical Monetary Policy." Journal of Political Economy, 104(4), 704-723.

[33] Khan, Aubhik, Robert G. King, and Alexander L. Wolman (2003). "Optimal Monetary Policy." Review of Economic Studies, 70(4), 825-860. 
[34] Kim, Jinill, and Francisco J. Ruge-Murcia (2009). "How much inflation is necessary to grease the wheels?," Journal of Monetary Economics, 56(3), 365-377.

[35] Lewis, Vivien (2010). "Optimal Monetary Policy and Firm Entry.” Mimeo, Ghent University.

[36] Ljungqvist, Lars, and Harald Uhlig (2000). "Tax Policy and Aggregate Demand Management under Catching Up with the Joneses." American Economic Review, 90(3), 356-366.

[37] Lucas, Robert E. Jr. (1987). "Models of Business Cycles." Oxford: Basil Blackwell.

[38] Lucas, Robert E. Jr., and Nancy L. Stokey (1983). "Optimal Fiscal and Monetary Policy in an Economy without Capital." Journal of Monetary Economics, 12, 55-93.

[39] Nekarda, Christopher J., and Valerie A. Ramey (2010). "The Cyclical Behavior of the PriceCost Markup." Mimeo, Board of Governors of the Federal Reserve System and U.C. San Diego.

[40] Petrin, Amil (2002). "Quantifying the Benefits of New Products: The Case of the Minivan." Journal of Political Economy, 110(4), 705-729.

[41] Rotemberg, Julio J. (1982) "Monopolistic Price Adjustment and Aggregate Output". Review of Economic Studies, 49(4), 517-531.

[42] Rotemberg, Julio J., and M. Woodford (1999). "The Cyclical Behavior of Prices and Costs." in Taylor, John B., and Michael Woodford, eds., Handbook of Macroeconomics, vol. 1B, Elsevier, Amsterdam, 1051-1135.

[43] Schmitt-Grohé, Stephanie, and Martin Uribe (2004a). "Optimal Fiscal and Monetary Policy under Imperfect Competition". Journal of Macroeconomics, 26(2), 183-209.

[44] Schmitt-Grohé, Stephanie, and Martin Uribe (2004b). "Optimal Fiscal and Monetary Policy under Sticky Prices". Journal of Economic Theory, 114(2), 198-230.

[45] Schmitt-Grohé, Stephanie, and Martin Uribe (2007). "Optimal Simple and Implementable Monetary and Fiscal Rules." Journal of Monetary Economics, 54(6), 1702-1725.

[46] Schmitt-Grohé, Stephanie, and Martin Uribe (2011). "The Optimal Rate of Inflation." in Friedman, Benjamin, and Michael Woodford, eds., Handbook of Monetary Economics, Volume 3B, Elsevier, San Diego CA, 653-722. 
[47] Siu, Henry E. (2004). "Optimal Fiscal and Monetary Policy with Sticky Prices." Journal of Monetary Economics, 51(3), 575-607.

[48] Smets, Franck and Rafael Wouters, 2007. "Shocks and Frictions in US Business Cycles: A Bayesian DSGE Approach," American Economic Review, 97(3), 586-606.

[49] Thomas, Carlos (2008). "Search and Matching Frictions and Optimal Monetary Policy." Journal of Monetary Economics, 55(5), 936-956.

[50] Trajtenberg, Manuel (1989). "Welfare Analysis of Product Innovations, with an Application to Computed Tomography Scanners." Journal of Political Economy, 97(2), 444-479.

[51] Weber, Henning (2011). "Optimal Inflation and Firms' Productivity Dynamics." Mimeo, Kiel IFW.

[52] Wolman, Alexander L. (2011), "The Optimal Rate of Inflation with Trending Relative Prices." Journal of Money, Credit and Banking, 43, 355-384

[53] Woodford, Michael (2003). Interest and Prices: Foundations of a Theory of Monetary Policy. Princeton University Press, Princeton, NJ.

[54] Woodford, Michael (2011). "Optimal Monetary Stabilization Policy," in Friedman, Benjamin, and Michael Woodford, eds., Handbook of Monetary Economics, Volume 3B, Elsevier, San Diego CA. 


\section{Appendix}

\section{A Ramsey-Optimal Policy and Variety}

The four first-order conditions with respect to labor, inflation, labor in the consumption sector, and the number of product varieties next period, obtained by solving the Ramsey problem (5) are, respectively:

$$
\begin{aligned}
& L_{t}:-h_{L}\left(L_{t}\right)-(1-\delta) \eta_{1, t} \frac{Z_{t}}{f_{E}}+\theta\left(N_{t}\right) \eta_{2, t} L_{C, t} h_{L L}\left(L_{t}\right)\left(1-\frac{\kappa}{2} \pi_{t}^{2}\right) \\
& +\eta_{3, t} h_{L L}\left(L_{t}\right) \frac{f_{E}}{Z_{t}}-\eta_{3, t-1}(1-\delta)\left(h_{L L}\left(L_{t}\right) \frac{f_{E}}{Z_{t}}-\frac{L_{C, t} h_{L L}\left(L_{t}\right)}{N_{t}}\right) \\
& =0 \text {, } \\
& \pi_{t}:-\frac{\pi_{t}}{1-\frac{\kappa}{2} \pi_{t}^{2}}-\eta_{2, t}\left[\begin{array}{c}
\theta\left(N_{t}\right) \pi_{t} L_{C, t} h_{L}\left(L_{t}\right)+\left(1-\theta\left(N_{t}\right)\right) \pi_{t} \\
+\left(1+2 \pi_{t}\right)+\beta(1-\delta) \pi_{t+1}\left(1+\pi_{t+1}\right) \frac{N_{t}}{N_{t+1}} \frac{\kappa \pi_{t}}{1-\frac{\kappa}{2}\left(\pi_{t+1}\right)^{2}}
\end{array}\right] \\
& +\eta_{2, t-1}(1-\delta) \frac{N_{t-1}}{N_{t}}\left(1-\frac{\kappa}{2} \pi_{t-1}^{2}\right) \frac{1+\frac{\kappa}{2} \pi_{t}^{2}+2 \pi_{t}}{\left(1-\frac{\kappa}{2} \pi_{t}^{2}\right)^{2}} \\
& =0 \text {, } \\
& L_{C, t}: \frac{1}{L_{C, t}}+(1-\delta) \eta_{1, t} \frac{Z_{t}}{f_{E}}+\theta\left(N_{t}\right) \eta_{2, t} h_{L}\left(L_{t}\right)\left(1-\frac{\kappa}{2} \pi_{t}^{2}\right)+\eta_{3, t-1}(1-\delta) \frac{h_{L}\left(L_{t}\right)}{N_{t}}=0, \\
& N_{t}: \beta \frac{\epsilon\left(N_{t+1}\right)}{N_{t+1}}+\eta_{1, t}-\eta_{1, t} \beta(1-\delta)-\beta \eta_{2, t+1} \theta^{\prime}\left(N_{t+1}\right)\left(1-\frac{\kappa}{2} \pi_{t+1}^{2}\right)\left[1-L_{C, t+1} h_{L}\left(L_{t+1}\right)\right] \\
& -\eta_{2, t} \beta(1-\delta) \kappa \pi_{t+1}\left(1+\pi_{t+1}\right) \frac{N_{t}}{N_{t+1}^{2}} \frac{1-\frac{\kappa}{2} \pi_{t}^{2}}{1-\frac{\kappa}{2} \pi_{t+1}^{2}} \\
& +\beta^{2}(1-\delta) \eta_{2, t+1} \kappa \pi_{t+2}\left(1+\pi_{t+2}\right) \frac{1-\frac{\kappa}{2} \pi_{t+1}^{2}}{1-\frac{\kappa}{2} \pi_{t+2}^{2}} \frac{1}{N_{t+2}}+\beta(1-\delta) \eta_{3, t} \frac{1-L_{C, t+1} h_{L}\left(L_{t+1}\right)}{N_{t}^{2}} \\
& =0 \text {, }
\end{aligned}
$$

where we used $\epsilon\left(N_{t}\right) \equiv \frac{\rho^{\prime}\left(N_{t}\right)}{\rho\left(N_{t}\right)} N_{t}$ in the last equation. 
The non-stochastic steady state is such that:

$$
\begin{gathered}
-h_{L}(L)-(1-\delta) \eta_{1}+\theta(N) \eta_{2} L_{C} h_{L L}(L)\left(1-\frac{\kappa}{2} \pi^{2}\right) \\
+\eta_{3} h_{L L}(L)-\eta_{3}(1-\delta) h_{L L}(L)\left(1-\frac{L_{C}}{N}\right)=0 \\
-\frac{\pi}{1-\frac{\kappa}{2} \pi^{2}}-\eta_{2}\left[\begin{array}{c}
\theta(N) \pi L_{C} h_{L}(L)+[1-\theta(N)] \pi \\
+(1+2 \pi)+\beta(1-\delta) \pi(1+\pi) \frac{\kappa \pi}{1-\frac{\kappa}{2}(\pi)^{2}}
\end{array}\right]+\eta_{2}(1-\delta) \frac{1+\frac{\kappa}{2} \pi^{2}+2 \pi}{1-\frac{\kappa}{2} \pi^{2}}=0 \\
\frac{1}{L_{C}}+(1-\delta) \eta_{1}+\theta(N) \eta_{2} h_{L}(L)\left(1-\frac{\kappa}{2} \pi^{2}\right)+\eta_{3}(1-\delta) \frac{h_{L}(L)}{N}=0 \\
\beta \frac{\epsilon(N)}{N}+\eta_{1}[1-\beta(1-\delta)]-\beta \eta_{2} \theta^{\prime}(N)\left[1-\frac{\kappa}{2} \pi^{2}\right]\left[1-L_{C} h_{L}(L)\right] \\
-(1-\beta) \beta(1-\delta) \kappa \frac{\eta_{2} \pi(1+\pi)}{N}+\beta(1-\delta) \eta_{3} \frac{1-L_{C} h_{L}(L)}{N^{2}}=0 \\
{[\theta(N)-1]\left[1-\frac{\kappa}{2} \pi^{2}\right]+\kappa[1-\beta(1-\delta)](1+\pi) \pi} \\
-\theta(N)\left(1-\frac{\kappa}{2} \pi^{2}\right) L_{C} h_{L}(L)=0 \\
\delta N-(1-\delta)\left(L-L^{C}\right)=0 \\
{[1-\beta(1-\delta)] h_{L}(L)-\beta(1-\delta) \frac{1-L_{C} h_{L}(L)}{N}=0}
\end{gathered}
$$

where the first four equations are the steady-state versions of the first-order conditions outlined above, and the last three correspond to the constraints of the Ramsey problem in Table 3.

When is a steady state with zero inflation $\pi=0$ a solution to the Ramsey problem? To answer this question, conjecture that $\pi=0$ in steady state. The first-order condition for the choice of inflation (the second equation above) then implies that the Lagrange multiplier on the Phillips curve is zero:

$$
\eta_{2}=0 .
$$

Naturally, the constraint associated to imperfect price adjustment is not binding in steady state when there is zero inflation. The other conditions evaluated at this equilibrium imply (we use the 
notation $\beta^{-1}=1+r$, so $r$ is the discount rate):

$$
\begin{gathered}
1+(1-\delta) \frac{\eta_{1}}{h_{L}(L)}-\frac{\eta_{3}}{L} \varphi[\delta+[\theta(N)-1](r+\delta)]=0 \\
1+(1-\delta) \eta_{1} L_{C}+(1-\delta) \frac{\theta(N)-1}{\theta(N)} \frac{\eta_{3}}{N}=0, \\
\epsilon(N)+(r+\delta) \eta_{1} N+(1-\delta) \frac{1}{\theta(N)} \frac{\eta_{3}}{N}=0, \\
\frac{\theta(N)-1}{\theta(N)}=L_{C} h_{L}(L), \\
\delta N=(1-\delta)\left(L-L^{C}\right) \\
h_{L}(L) N=\frac{1-\delta}{r+\delta} \frac{1}{\theta(N)} .
\end{gathered}
$$

The second and third equations imply:

$$
1+(1-\delta) \eta_{1} L_{C}-\epsilon(N)[\theta(N)-1]-[\theta(N)-1](r+\delta) \eta_{1} N=0
$$

But the fourth and sixth equations imply:

$$
[\theta(N)-1](r+\delta) N=(1-\delta) L_{C}
$$

which substituted into (11) yields:

$$
\epsilon(N)=\frac{1}{\theta(N)-1}
$$

This proves the result.

\section{B Price Indexation}

In this Appendix, we outline some of the implications of price indexation for Ramsey-optimal monetary policy. We assume that rather than paying the adjustment cost when deviating from zero-inflation, as implied by (1), firms index to past inflation and pay an adjustment cost given $\mathrm{by}^{24}$ :

$$
\operatorname{pac}_{t}(\omega) \equiv \frac{\kappa}{2}\left[\frac{p_{t}(\omega)}{p_{t-1}(\omega)}\left(\frac{p_{t-1}(\omega)}{p_{t-2}(\omega)}\right)^{-\gamma}-1\right]^{2} \frac{p_{t}(\omega)}{P_{t}} y_{t}^{D}(\omega),
$$

\footnotetext{
${ }^{24} \mathrm{~A}$ simple indexation scheme whereby firms index to a constant inflation rate $\tilde{\pi}$, rather than past inflation, would merely imply that the optimal long-run inflation rate is uniformly increased by the constant $\tilde{\pi}$, without affecting any of the other results.
} 
where $\gamma \in[0,1]$ is the indexation parameter. Under this indexation scheme, it can be easily shown that the long-run Phillips curve becomes:

$$
\mu(\pi)-1=\frac{\theta}{(\theta-1)\left\{1-\frac{\kappa}{2}\left[(1+\pi)^{1-\gamma}-1\right]^{2}\right\}+\kappa \frac{r+\delta}{1+r}(1+\pi)^{1-\gamma}\left[(1+\pi)^{1-\gamma}-1\right]}-1
$$

Note that this nests the no-indexation case when $\gamma=0$ and the full-indexation case when $\gamma=1$. Under full indexation, however, the steady-state inflation rate will be indeterminate: There is no long-run cost of using inflation ((12) evaluated at the steady-state implies pac $=0)$ and no benefit of inflation (the long-run Phillips curve (13) is vertical $\mu=\theta /(\theta-1)$ ). For values of $\gamma$ in the open interval $(0,1)$, our long-run results change as follows. The optimal rate of inflation (deflation) is increasing (in absolute value) with the indexation parameter $\gamma$. When indexation is almost full $(\gamma$ is close to 1 ) the optimal rate of long-run inflation (deflation) is indeed very large.

The reasons why indexation implies larger deviations from long-run price stability are twofold: First, indexation lowers the welfare cost associated with a given long-run inflation rate (the steadystate adjustment cost $P A C=\frac{\kappa}{2}\left((1+\pi)^{1-\gamma}-1\right)^{2} Y^{C}$ is decreasing in $\left.\gamma\right)$. Second, indexation causes the long-run Phillips curve to steepen, and hence requires larger inflation rates to achieve a certain change in long-run markup. Figure B.1 illustrates this mechanism, plotting the LRPC for a positive indexation parameter (in dashed-dot line) along with the LRPC for no indexation previously plotted in Figure 1 (solid line). The figure illustrates that in order to achieve a certain movement in long-run markup, necessary in order to bring it closer to the benefit of variety, a higher value of long-run inflation (or deflation) needs to be chosen by the central bank. 


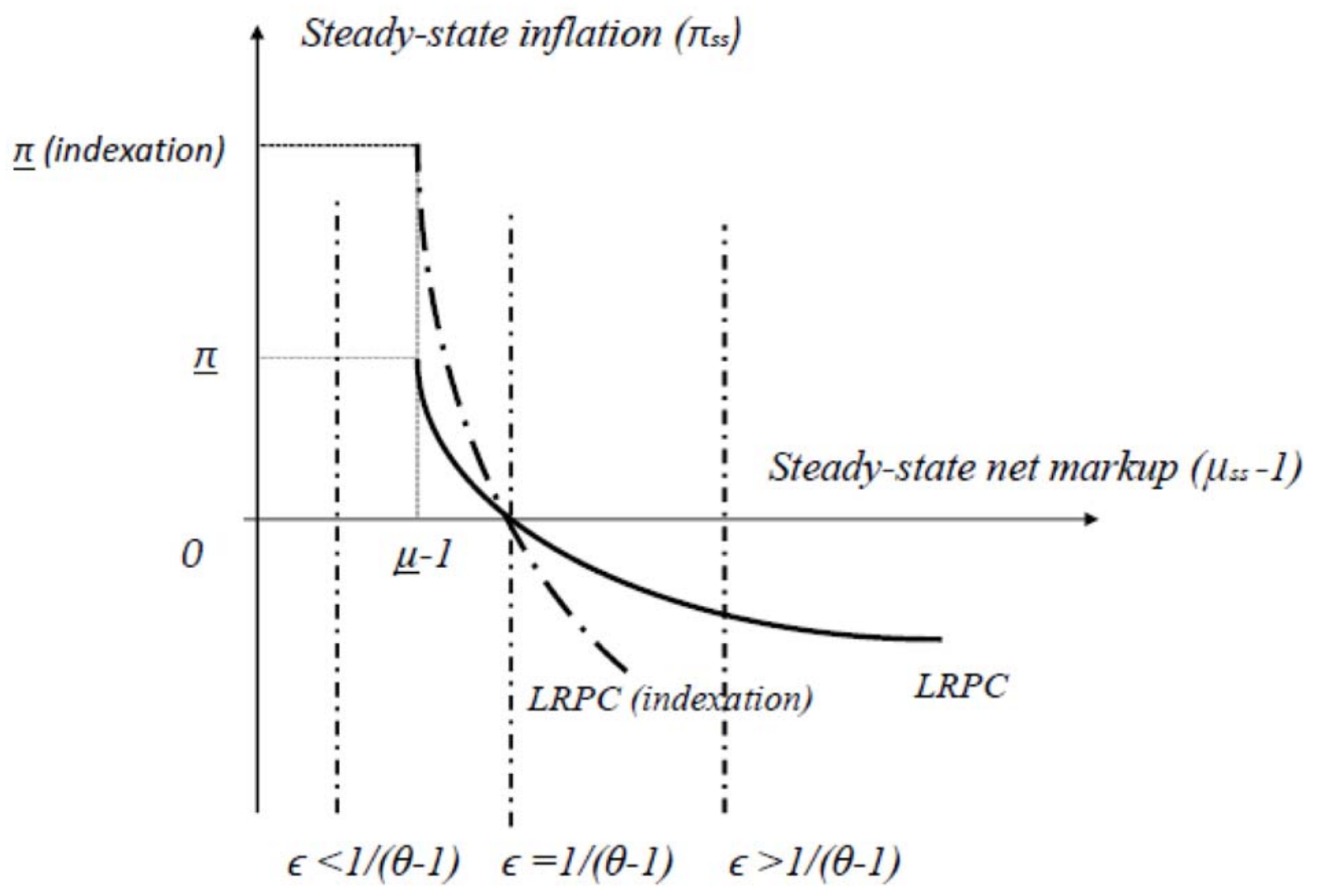

Figure B.1: The Long-run Phillips curve with and without indexation (dashed and solid curve, respectively).

Figure B.2 illustrates these results quantitatively, plotting the optimal long-run rate of inflation for C.E.S. preferences as a function of the indexation parameter $\gamma$, for the two extreme value of the benefit of variety: $\epsilon=0$ and $\epsilon=1$, respectively. ${ }^{25}$ For empirically plausible degrees of indexation (estimated for instance by Smets and Wouters, 2007, in the range between 0.25 and 0.5), optimal long-run inflation rates range from around 6 percent inflation (for $\epsilon=0$ ) to around 10 percent deflation (for $\epsilon=1$ ). A similar picture occurs under translog preferences (not plotted), where the optimal long-run rate of inflation, given $\sigma=0.353$, ranges from 1.03 percent under no indexation to approximately 10 percent when $\gamma=0.9$ (results are available upon request).

\footnotetext{
${ }^{25}$ The domain of $\gamma$ is restricted to values lower than 0.9 because, for larger values, the optimal rate of long-run inflation (deflation) becomes extremely large (close to 600 percent inflation and 300 percent deflation, respectively, for $\gamma=0.99)$.
} 


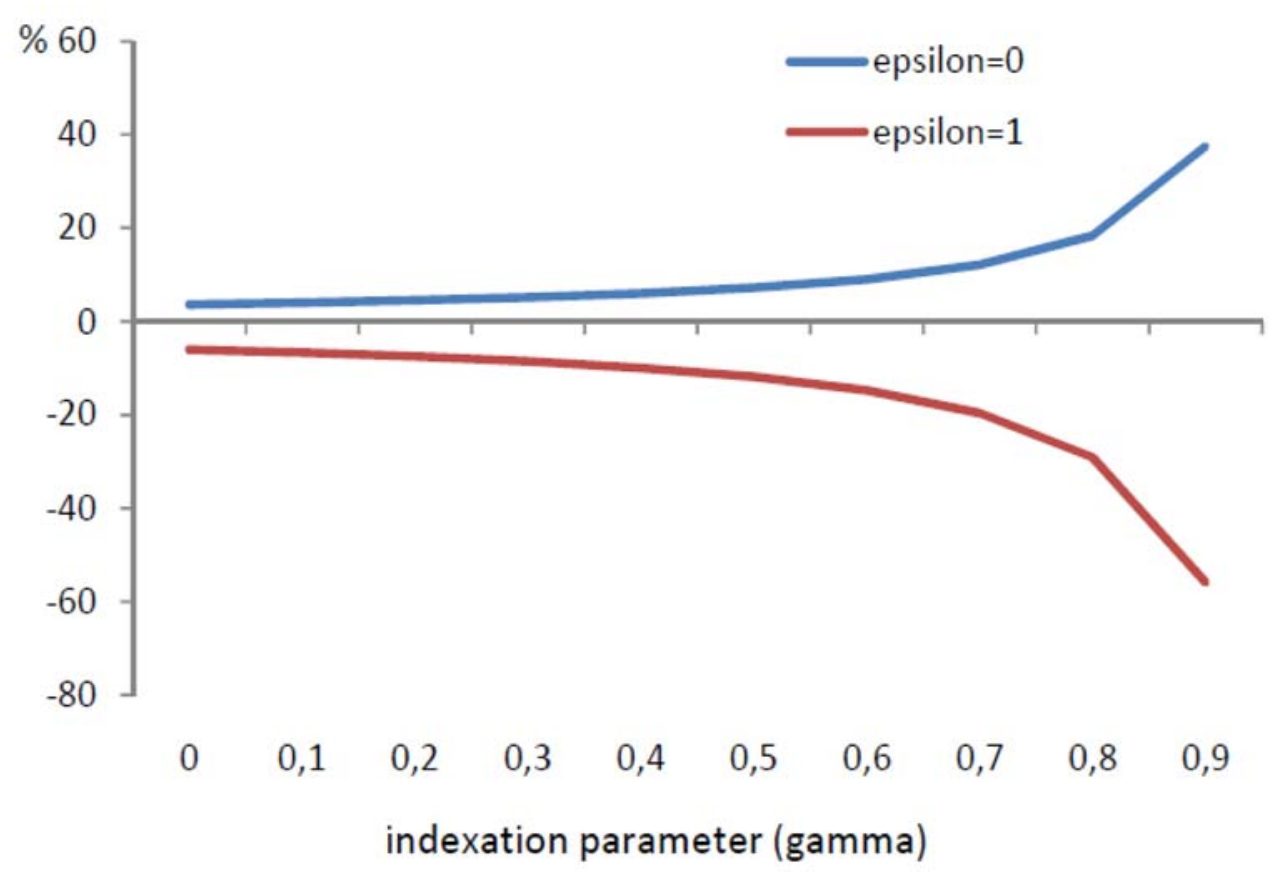

Figure B.2: The optimal long-run inflation rate as a function of the indexation parameter $\gamma$.

Figure B.3 illustrates the implications of price indexation for short-run optimal policy, by plotting the impulse responses to a productivity shock under C.E.S. preferences with no benefit from variety $(\epsilon=0)$ for two extreme values of the indexation parameter $\gamma(0$ and 0.9$)$. Indexation, by the same logic that applied to the long run, implies higher optimal variation in short-run inflation rates and the price level. But the implied movements are still quantitatively small: The maximum value of inflation is 0.25 basis points (attained after 10 quarters), translating into an increase in the price level of 3.7 percent. Most importantly, the paths of real variables (consumption, hours, and number of firms) are invariant to the indexation parameter: Indexation makes inflation less costly, but it also makes the Phillips curve more vertical, meaning that a larger inflation rate has a smaller effect on real variables. ${ }^{26}$ We therefore conclude that indexation affects significantly the optimal monetary policy prescriptions in the long run, but not in the short run.

\footnotetext{
${ }^{26}$ A similar result occurs under translog preferences: Responses of real variables are invariant to the degree of indexation, and optimal deflation under indexation attains a maximum of 0.06 basis points after 10 quarters, translating into a fall in the price level of around 1 percent; results are available upon request.
} 

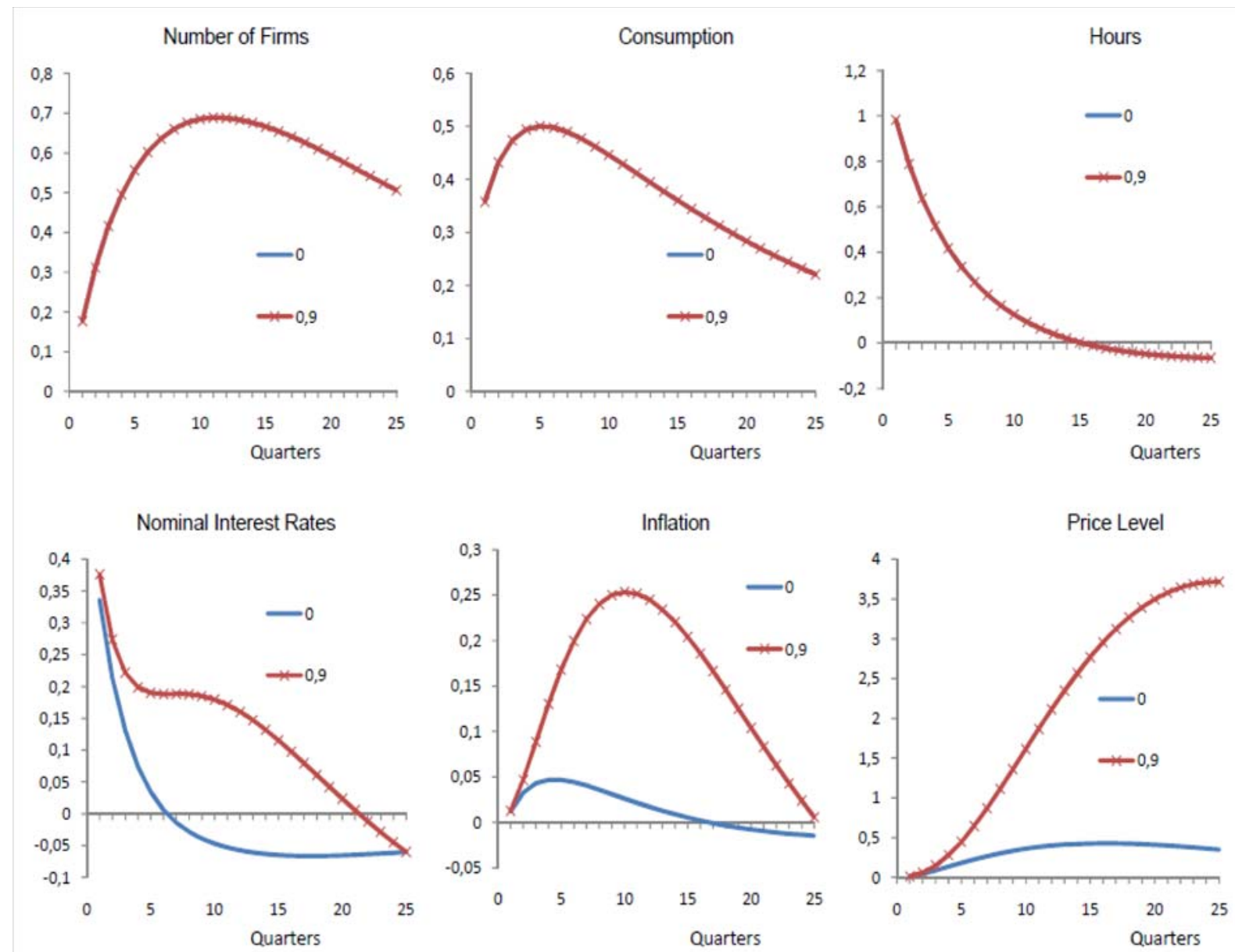

Figure B.3: Impulse responses to a productivity shock for C.E.S. preferences with $\epsilon=0$ under Ramsey policy, under no indexation $\gamma=0$ (blue line) and indexation (red, crossed line) $\gamma=0.9$. Inflation and interest rate are in basis points deviations, the rest in percentage deviations from steady state. 